\title{
Finite element analysis of a modified progressive damage model for composite laminates under low-velocity impact
}

\author{
Junjie Zhou ${ }^{\mathrm{a}, \mathrm{b}, *}$, Pihua Wen ${ }^{\mathrm{b}}$, Shengnan Wang ${ }^{\mathrm{a}, *}$ \\ ${ }^{a}$ School of Aeronautics, Northwestern Polytechnical University, Xi'an 710072, China \\ ${ }^{b}$ School of Engineering and Materials Science, Queen Mary University of London, London E1 4NS, UK
}

\begin{abstract}
In this paper, a 3D finite element model is established in ABAQUS/Explicit based on a modified progressive damage model to study the dynamic mechanical response and damage development in cross-ply composite laminates subjected to low-velocity impact. The 3D Hashin criterion and the damage evolution model with the through-thickness normal stress component $\sigma_{33}$ are applied to predict the intra-laminar damage initiation and evolution. The cohesive elements with the bilinear traction-separation relationship are inserted between layers to predict the inter-laminar delamination induced by impact loading. A user-material subroutine VUMAT involving the modified progressive damage model of intra-laminar and inter-laminar damage is coded and implemented in the finite element package ABAQUS/Explicit. The numerical results of three different impact energies $(7.35,11.03$ and $14.70 \mathrm{~J}$ ) are analyzed by the impact force-time, force-displacement and energy-time histories curves as well as different damage modes. The respectable relationship between numerical simulation and experimental result indicates that the proposed modified method is more suitable for low-velocity impact on composite laminates under different impact energies than the previous method without $\sigma_{33}$. Moreover, the effects of $S_{m t}$ and $S_{m c}$ on global mechanical response and local damage predictions for laminates are discussed in detail. It can be concluded that both of the coefficients should be adopted between 0.93 and 0.96 when using this damage model to simulate composite laminates under low-velocity impact.
\end{abstract}

Keywords: Composite laminates, Low-velocity impact, Failure criteria, Damage evolution, Finite element analysis

\section{Introduction}

During the last decades, composite materials have been applied in various structures because of their high specific stiffness and strength ratio, especially in aerospace structures where barely visible impact damage (BVID) can be a critical issue [1]. However, their poor impact resistance, which is a disadvantage of composite materials, raises a large challenge to the design and application of composites [2, 3]. Considering the high cost of testing and the inability to accurately monitor the BVID, numerical modeling is considered as the most efficient tool which could simulate the impact and predict the complicated internal damage mechanisms in a relatively short time. Therefore, the finite element modeling is always preferred by the researchers to study the impact damage issues of composite laminates.

The complex composite material impact behaviour can be simulated based on the constitutive models provided $[4,5,6$, $7,8]$. Among these well developed numerical techniques, the progressive damage model (PDM) has become the most popular simulation scheme which considers damage initiation and subsequent stiffness degradation $[6,8,9,10,11,12,13]$. With regrad to damage initiation determination for composites, the interactive criteria with separate expressions to assess fiber and

\footnotetext{
${ }^{*}$ Corresponding author

Email addresses: junjie.zhou@qmul .ac.uk (Junjie Zhou), wangshna@nwpu.edu.cn (Shengnan Wang)
}

matrix damage under tensile and compression loading have been used widely, including the Hashin [14, 15], Chang-Chang [16] and Hou [17, 18] criteria. The three-dimensional Hashin criterion contains the through-thickness normal stress component $\sigma_{33}$ in matrix failure criterion, which is unique among these criteria. Once the failure criterion is satisfied, an appropriate damage evolution model needs to be proposed in order to describe the loss of stiffness. Some researchers used the predefined constants for stiffness degradation rule to simulate the process of damage accumulation around the damaged area $[19,20]$. Obviously, this approach is not applicable for a wide range of situations. Due to the involvement of mechanical parameters, the equivalent displacement method in damage evolution model is now widely employed by researchers for predicting the progressive damage behavior of composite materials $[6,10,11,12,21,22]$. In order to control the shear stiffness loss caused by the matrix failure in tension and compression, the relevant coefficients $S_{m t}$ and $S_{m c}$ are introduced in the degraded stiffness matrix $[10,12,22]$. Nevertheless, the equivalent displacement and stress for the matrix failure modes are expressed without $\sigma_{33}$ in their works, which is not appropriate with the 3D Hashin criterion for matrix. Therefore, a proper damage evolution method containing $\sigma_{33}$ for this situation should be posed and validated.

Among the typical damage modes occurring in the composite laminates, delamination is considered to be the most critical mode since it may propagate undetectably and lead to un- 
foreseen collapse of the structure [23]. Due to the essentiality of delamination, virtual crack closure technique (VCCT) [24] and cohesive zone model (CZM) [25] have been adopted by researchers in numerical simulation. However, the VCCT is required to predefine the crack initiation and needs to employ adaptive re-meshing technique in the front of delamination. On the contrary, CZM uses strength-based criterion and fracture energy criterion to predict the damage initiation and evolution, which overcomes the disadvantage of VCCT. The bilinear traction-separation law is commonly used when the CZM-based interface elements are chosen to simulate the delamination [21, 26, 27, 28, 29].

In this paper, a 3D finite element model is established in ABAQUS/Explicit to simulate the low-velocity impact damage in cross-ply composite laminates. The PDM including the Hashin criterion and a modified computational method of equivalent displacement with $\sigma_{33}$ in damage evolution model is proposed and coded in the user-defined subroutine (VUMAT). Interface cohesive elements with the bilinear tractionseparation law are inserted between plies to simulate delamination. The general contact algorithm is implemented in order to simulate the contact between the impactor and the plate surface, while the appropriate contact pair properties are defined in the contact between layers. The numerical results are validated and discussed against the experimental results reported by Shi [21]. The effects of the coefficients $S_{m t}$ and $S_{m c}$ on global mechanical response and local damage predictions for laminates are then discussed in detail.

\section{Composite damage model for impact}

Generally speaking, the composite damage caused by lowvelocity impact can be classified by two main failure categories: (1) Intra-laminar failure which occurs within a ply including fiber tensile and compressive breakage, and matrix tensile and compressive damage. (2) Inter-laminar failure or delamination which occurs between neighbor plies. The impact damage process can be simulated by progressive damage models, which consists of failure initiation criteria , damage evolution model and continuum damage model.

\subsection{Intra-laminar damage}

\subsubsection{Failure initiation criteria}

Hashin's failure criterion [15] is one of the most famous criteria for predicting damage initiation in one layer of composite laminates, which is wildly used in both academic and engineering fields. In the present study, the three-dimensional Hashin criterion is implemented, which includes through-thickness normal stress component in matrix failure. The four different failure modes are given as follows:

Fiber tensile failure $\left(\sigma_{11} \geqslant 0\right)$

$$
F_{f t}=\left(\frac{\sigma_{11}}{X_{T}}\right)^{2}+\alpha\left(\frac{\sigma_{12}}{S_{12}}\right)^{2}+\alpha\left(\frac{\sigma_{13}}{S_{13}}\right)^{2} \geqslant 1
$$

Fiber compressive failure $\left(\sigma_{11}<0\right)$

$$
F_{f c}=\left(\frac{\sigma_{11}}{X_{C}}\right)^{2} \geqslant 1
$$

Matrix tensile failure $\left(\sigma_{22}+\sigma_{33} \geqslant 0\right)$

$$
\begin{aligned}
F_{m t}= & \left(\frac{\sigma_{22}+\sigma_{33}}{Y_{T}}\right)^{2}+\frac{1}{S_{23}^{2}}\left(\sigma_{23}^{2}-\sigma_{22} \sigma_{33}\right)+ \\
& \left(\frac{\sigma_{12}}{S_{12}}\right)^{2}+\left(\frac{\sigma_{13}}{S_{13}}\right)^{2} \geqslant 1
\end{aligned}
$$

Matrix compressive failure $\left(\sigma_{22}+\sigma_{33}<0\right)$

$$
\begin{aligned}
F_{m c}= & \left(\frac{\sigma_{22}+\sigma_{33}}{2 S_{23}}\right)^{2}+\frac{\sigma_{22}+\sigma_{33}}{Y_{C}}\left[\left(\frac{Y_{C}}{2 S_{23}}\right)^{2}-1\right]+ \\
& \frac{1}{S_{23}^{2}}\left(\sigma_{23}^{2}-\sigma_{22} \sigma_{33}\right)+\left(\frac{\sigma_{12}}{S_{12}}\right)^{2}+\left(\frac{\sigma_{13}}{S_{13}}\right)^{2} \geqslant 1
\end{aligned}
$$

In the above equations, $\sigma_{i j}(i, j=1,2,3)$ is the effective stress tensor; $X_{T}$ and $X_{C}$ are the tensile and compressive strengths of the unidirectional composite laminate in the fiber direction; $Y_{T}$ and $Y_{C}$ are the tensile and compressive strengths in the transverse direction; $S_{12}, S_{13}$ and $S_{23}$ are shear strengths respectively; $\alpha$ is the shear failure coefficient applied to determine the contribution of shear stresses on the fiber tensile failure. In the present work, $\alpha$ is set as 1 .

\subsubsection{Damage evolution model}

Once a failure initiation criterion is satisfied, the damage evolution model needs to be defined. When the behavior of the material model becomes softened, the damage of material exhibits localizing characteristics as the energy dissipated decreases upon mesh refinement. In order to solve the problem, the crack band model developed by Bažant and Oh [30] was successfully implemented by Lapczyk and Hurtado [6] and Fang et al. [12] and Chao et al. [11] in their damage models. The element dissipated energy can then be expressed as:

$$
G_{I}=\frac{1}{2} \sigma_{e q}^{f} \varepsilon_{e q}^{f} l_{c}
$$

where $G_{I}$ is the fracture energy density of failure mode $I ; \sigma_{e q}^{f}$, $\varepsilon_{e q}^{f}$ are the equivalent peak stress and the equivalent failure strain, respectively; $l_{c}$ is the characteristic length of element, which is considered to be equal to the cube root of the element volume in the present study.

The evolution of damage variable for each failure mode $I$ is expressed as:

$$
d_{I}=\frac{\delta_{I, e q}^{f}\left(\delta_{I, e q}-\delta_{I, e q}^{0}\right)}{\delta_{I, e q}\left(\delta_{I, e q}^{f}-\delta_{I, e q}^{0}\right)} \quad\left(d_{I} \in[0,1], I=f t, f c, m t, m c\right)
$$

where $\delta_{I, e q}^{f}$ is the damage equivalent displacement of the corresponding failure mode at final failure; $\delta_{I, e q}^{0}$ is the equivalent displacement for damage initiation; they can be computed by the following equations:

$$
\begin{gathered}
\delta_{I, e q}^{f}=\frac{2 G_{I}}{\sigma_{I, e q}^{0}} \\
\delta_{I, e q}^{0}=\frac{\delta_{I, e q}}{\sqrt{F_{I}}}
\end{gathered}
$$


Table 1: Equivalent displacement and stress of each failure mode

\begin{tabular}{lll}
\hline Failure modes & Equivalent displacement & Equivalent stress \\
\hline Fiber tension & $\delta_{f t, e q}=l_{c} \sqrt{\left(\left\langle\varepsilon_{11}\right\rangle^{2}+\alpha \varepsilon_{12}^{2}+\alpha \varepsilon_{13}^{2}\right)}$ & $\sigma_{f t, e q}=\frac{l_{c}\left(\left\langle\sigma_{11}\right\rangle\left\langle\varepsilon_{11}\right\rangle+\alpha \sigma_{12} \varepsilon_{12}+\alpha \sigma_{13} \varepsilon_{13}\right)}{\delta_{f t, e q}}$ \\
Fiber compression & $\delta_{f c, e q}=l_{c}\left\langle-\varepsilon_{11}\right\rangle$ & $\sigma_{f c, e q}=\frac{l_{c}\left\langle-\sigma_{11}\right\rangle\left\langle-\varepsilon_{11}\right\rangle}{\delta_{f c, e q}}$ \\
Matrix tension & $\delta_{m t, e q}=l_{c} \sqrt{\left(\left\langle\varepsilon_{22}\right\rangle^{2}+\left\langle\varepsilon_{33}\right\rangle^{2}+\varepsilon_{12}^{2}+\varepsilon_{23}^{2}+\varepsilon_{13}^{2}\right)}$ & $\sigma_{m t, e q}=\frac{l_{c}\left(\left\langle\sigma_{22}\right\rangle\left\langle\varepsilon_{22}\right\rangle+\left\langle\sigma_{33}\right\rangle\left\langle\varepsilon_{33}\right\rangle+\sigma_{12} \varepsilon_{12}+\sigma_{23} \varepsilon_{23}+\sigma_{13} \varepsilon_{13}\right)}{\delta_{m t, e q}}$ \\
Matrix compression & $\delta_{m c, e q}=l_{c} \sqrt{\left(\left\langle-\varepsilon_{22}\right\rangle^{2}+\left\langle-\varepsilon_{33}\right\rangle^{2}+\varepsilon_{12}^{2}+\varepsilon_{23}^{2}+\varepsilon_{13}^{2}\right)}$ & $\sigma_{m c, e q}=\frac{l_{c}\left(\left\langle-\sigma_{22}\right\rangle\left\langle-\varepsilon_{22}\right\rangle+\left\langle-\sigma_{33}\right\rangle\left\langle-\varepsilon_{33}\right\rangle+\sigma_{12} \varepsilon_{12}+\sigma_{23} \varepsilon_{23}+\sigma_{13} \varepsilon_{13}\right)}{\delta_{m c, e q}}$ \\
\hline
\end{tabular}

$$
\sigma_{I, e q}^{0}=\frac{\sigma_{I, e q}}{\sqrt{F_{I}}}
$$

where $F_{I}$ is the value of damage initiation criterion; $\delta_{I, e q}$ and $\sigma_{I, e q}$ are the equivalent displacement and equivalent stress for a failure mode respectively.

In the previous works of literature $[12,11,21,10]$, the through-thickness normal stress $\sigma_{33}$ was ignored when calculating the equivalent displacement and equivalent stress for matrix failure modes. However, the 3D Hashin's matrix failure criterion is judged according to $\sigma_{22}+\sigma_{33}$. It is inappropriate to compute $\delta_{I, e q}$ and $\sigma_{I, e q}$ without $\sigma_{33}$. In the present work, the modified formulas based on Ref.[11], including the throughthickness normal stress component, are proposed and listed in Table 1, where the symbol \langle\rangle represents the Macaulay operator. The effects on simulation results of the two calculation methods are discussed in the chapter 4 .

\subsubsection{Continuum damage model}

For composite laminates, each ply is generally treated as a transversely isotropic material. It means that the transversely isotropic constitutive equation with only five independent constants is implemented for undamaged lamina. By adding different damage variables to modify the constitutive equations, the degraded compliance matrix $S_{d}$ is expressed as:

$$
S_{d}=\left[\begin{array}{cccccc}
\frac{1}{d_{f} E_{11}} & -\frac{v_{21}}{E_{22}} & -\frac{v_{31}}{E_{33}} & & & \\
-\frac{v_{12}}{E_{11}} & \frac{1}{d_{m} E_{22}} & -\frac{v_{32}}{E_{33}} & & & \\
-\frac{v_{13}}{E_{11}} & -\frac{v_{23}}{E_{22}} & \frac{1}{E_{33}} & \frac{1}{d_{f} d_{m} G_{12}} & \frac{1}{} & \\
& & & & \frac{1}{d_{f} d_{m} G_{23}} & \\
& & & & & \frac{1}{d_{f} d_{m} G_{31}}
\end{array}\right]
$$

where $d_{f}$ and $d_{m}$ represent the fiber and matrix damage variables, respectively. In the meantime, the corresponding degraded stiffness matrix $C_{d}$ is shown as:

$$
C_{d}=\frac{1}{\Delta}\left[\begin{array}{lc}
d_{f} E_{11}\left(1-d_{m} v_{23} v_{32}\right) & d_{f} d_{m} E_{11}\left(v_{21}+v_{23} v_{31}\right) \\
d_{m} E_{22}\left(1-d_{f} v_{13} v_{31}\right) \\
\end{array}\right.
$$$$
\left\{\begin{array}{l}
d_{f}=\left(1-d_{f t}\right)\left(1-d_{f c}\right) \\
d_{m}=\left(1-S_{m t} d_{m t}\right)\left(1-S_{m c} d_{m c}\right) \\
\Delta=1-d_{f} d_{m} v_{12} v_{21}-d_{m} v_{23} v_{32}-d_{f} v_{13} v_{31}-2 d_{f} d_{m} v_{21} v_{32} v_{13}
\end{array}\right.
$$

where $d_{f t}, d_{f c}, d_{m t}, d_{m c}$ are the damage variables for fiber and matrix damage under tensile and compression loads that are calculated by damage evolution model. $S_{m t}$ and $S_{m c}$ are introduced coefficients to control the shear stiffness loss due to failure of the matrix in tension and compression [10, 12, 22]. In the present study, $S_{m t}$ and $S_{m c}$ are set as 0.96 . The effects of their values on the simulation results are discussed in the chapter 4 .

$$
\left.\begin{array}{cccc}
d_{f} E_{11}\left(v_{31}+d_{m} v_{21} v_{32}\right) & & & \\
d_{m} E_{22}\left(v_{32}+d_{f} v_{12} v_{31}\right) & & & \\
E_{33}\left(1-d_{f} d_{m} v_{12} v_{21}\right) & & & \\
& \Delta d_{f} d_{m} G_{12} & & \\
& & \Delta d_{f} d_{m} G_{23} & \\
& & & \Delta d_{f} d_{m} G_{13}
\end{array}\right]
$$

\subsection{Inter-laminar damage}

The cohesive zone elements based on a bilinear tractionseparation relationship are adopted to simulate the inter-laminar delamination at the interface of adjacent plies in the composite laminates. Delamination initiation and the corresponding reduction behavior are determined by mixed-mode loading. Therefore, both quadratic failure criterion and the Benzeggagh and Kenane (B-K) criterion [31] are used to predict the initiation and propagation of delamination damage, expressed in Eqs.(13) and (14), respectively.

$$
\frac{\left\langle t_{n}\right\rangle^{2}}{N^{2}}+\frac{t_{s}^{2}}{S^{2}}+\frac{t_{t}^{2}}{T^{2}}=1
$$


where $t_{n}, t_{s}$ and $t_{t}$ represent the normal and shear tractions; $N$, $S$ and $T$ denote the interface normal and shear strength.

$$
G^{C}=G_{n}^{C}+\left(G_{s}^{C}-G_{n}^{C}\right)\left\{\frac{G_{S}}{G_{T}}\right\}^{\eta}
$$

where $G^{C}, G_{n}^{C}$ and $G_{s}^{C}$ are the total, normal and shear critical fracture energy, respectively; $G_{S}$ is the dissipated energy in the out-of-plane direction; $G_{T}$ is the total dissipated energy in all three directions; $\eta$ is the relevant material coefficient in the B-K formula.

\section{Finite element modeling of low-velocity impact}

\subsection{Finite element model and boundary conditions}

The 3D finite element model is established based on the available experimental data given by Shi [21, 29]. The $2 \mathrm{~mm}$ thick composite laminates built as a circular plate with $75 \mathrm{~mm}$ in diameter consist of eight layers with each $0.25 \mathrm{~mm}$ thickness in the stacking sequences $[0 / 90]_{2 s}$. Global and local coordinates are defined to account for ply orientations and material behavior.

The hemispherical head cylindrical impactor with $15 \mathrm{~mm}$ in diameter is modeled as an analytical rigid body. The initial velocity of $3.83 \mathrm{~m} / \mathrm{s}$ along the $\mathrm{z}$-axis and the concentrated mass of $1,1.5$ and $2 \mathrm{~kg}$ are assigned to the impactor in order to obtain three impact energies of 7.35, 11.03 and $14.70 \mathrm{~J}$ respectively.

The distance between the external surface of impactor and the topface of plate is set as $0 \mathrm{~mm}$. All freedoms along the periphery of the plate are constrained to zero to simulate the experimental clamped conditions. Fig. 1 demonstrates the finite element model of cross-ply composite laminates under lowvelocity impact.

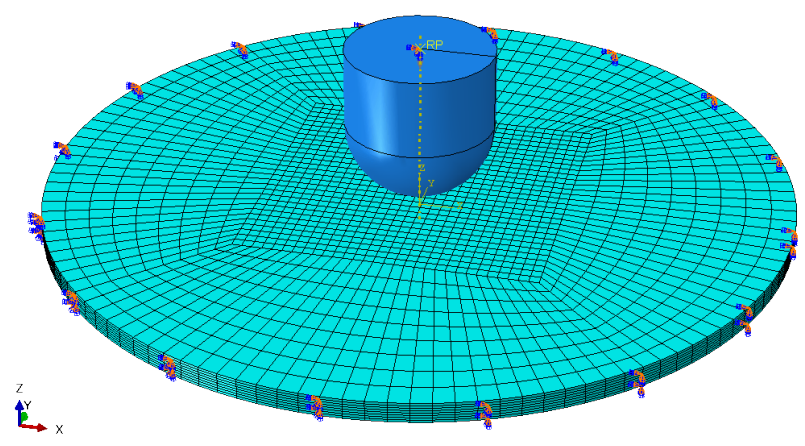

Figure 1: Finite element model of cross-ply composite laminates under lowvelocity impact

\subsection{Element types and mesh density}

The eight-node solid elements with reduced integration (C3D8R) are used in the plate. The relax stiffness hourglass control method is implemented to avoid fake deformation of elements. In order to improve the computational accuracy and efficiency, the mesh with element size of $1 \mathrm{~mm} \times 1 \mathrm{~mm}$ is used in the impact zone while the coarser mesh is employed in the rest of part. In addition, the zero-thickness eight-node three dimension cohesive elements (COH3D8) are inserted between adjacent layers to simulate delamination. The element deletion is not allowed in the numerical model because there was no penetration observed in the experiment [21]. Therefore, the mesh of composite laminates consists of 15840 C3D8R elements and $13860 \mathrm{COH} 3 \mathrm{D} 8$ elements.

\subsection{Material properties and contact definition}

The detailed material properties of unidirection laminate used in the present study are listed in Tabel 2. The values of each material property are taken from the Refs.[21, 29].

Table 2: Material properties of unidirectional laminate

\begin{tabular}{ll}
\hline Density & $1600 \mathrm{~kg} / \mathrm{m}^{3}$ \\
& $E_{11}=153 \mathrm{GPa} ; E_{22}=E_{33}=10.3 \mathrm{GPa} ;$ \\
Stiffness properties & $G_{12}=G_{13}=6 \mathrm{GPa} ; G_{23}=3.7 \mathrm{GPa} ;$ \\
& $v_{12}=v_{13}=0.3 ; v_{23}=0.4$ \\
& $X_{T}=2537 \mathrm{MPa} ; X_{C}=1580 \mathrm{MPa} ;$ \\
Strength properties & $Y_{T}=82 \mathrm{MPa} ; Y_{C}=236 \mathrm{MPa} ;$ \\
& $S_{12}=S_{13}=90 \mathrm{MPa} ; S_{23}=40 \mathrm{MPa}$ \\
Fracture energy & $G_{f t}=91.6 \mathrm{~N} / \mathrm{mm} ; G_{f c}=79.9 \mathrm{~N} / \mathrm{mm} ;$ \\
& $G_{m t}=0.22 \mathrm{~N} / \mathrm{mm} ; G_{m c}=1.1 \mathrm{~N} / \mathrm{mm}$ \\
\hline
\end{tabular}

As for interface cohesive element, Liu [10] compared the effects of different interface strengths on the delamination damage and chose the appropriate values for cohesive element in his work. The values of material properties used in the present study are listed in Table 3.

Table 3: Material properties of interface cohesive elements

\begin{tabular}{ll}
\hline Elastic modulus & $E_{n}=E_{s}=E_{t}=5 \mathrm{GPa} / \mathrm{mm}$ \\
Strength properties & $N=S=T=30 \mathrm{MPa}$ \\
Fracture energy & $G_{n}^{C}=0.6 \mathrm{~N} / \mathrm{mm} ; G_{s}^{C}=0.6 \mathrm{~N} / \mathrm{mm}$ \\
Relevant coefficient $\eta$ & 1.45 \\
\hline
\end{tabular}

A general contact algorithm in ABAQUS/Explicit is adopted to simulate contact between the impactor and the plate, as well as ply-to-ply in the laminate. The penalty method with a friction coefficient is used to describe the tangential behavior, while hard contact method is employed to describe the normal behavior. Schön [32] and Bing [33] studied the friction between composite surfaces and the effective method to achieve friction coefficient. For a $0^{\circ} / 0^{\circ}$ interface the value of $\mu=0.2$ was suggested, while $\mu=0.8$ was recommended for the interface between neighbouring $90^{\circ}$ plies. Therefore, the average friction coefficient of $\mu=0.5$ is used between the layers, and the value of 0.3 is applied between the impactor and the plate.

\section{Numerical results and discussion}

The numerical results of three different impact energies $(7.35,11.03$ and $14.70 \mathrm{~J})$ are compared to the experimental data 
in Ref. [21] to validate the proposed model. During the process of simulating, the impact force-time, force-displacement and energy-time histories curves are recorded and the damages of matrix and delamination are displayed. The benefits of the proposed calculating equivalent displacement method with $\sigma_{33}$ are discussed, comparing the previous method without $\sigma_{33}$. In addition, the effect of the coefficients to control shear stiffness loss on the global mechanical response is studied.

\subsection{Global mechanical response}

Fig. 2 illustrates the comparison of two numerical results and experimental force-time curves under three impact energies. Method A represents the previous damage model [10] ignored the through-thickness normal stress $\sigma_{33}$ when calculating the equivalent displacement and equivalent stress for matrix failure modes. Method B denotes the proposed progressive damage model including $\sigma_{33}$ in the present work. By comparing Fig. 2(a-c), obviously, the maximum force increases with the increase of impact energy, while the difference between the curves obtained by the two methods becomes smaller, especially the curves are basically the same in Fig. 2(c). In the initial phase of contact, some oscillations can be seen due to the elastic vibration induced by the initial contact between the impactor and the plate. After that, intense oscillations indicate the initiation of damage. Before reaching the peak value, the force of method $\mathrm{A}$ is always a little bigger than the force of method B, especially in the level of 7.45J. The reason for this phenomenon should be that the stiffness matrix of method $B$ degenerates more continuously and does not cause large oscil(ai) pns. Due to the addition of $\sigma_{33}$ in the method B, the damage varlable $d_{I}$ is easier to reach the maximum value 1 than the method A when using the formulas of equivalent displacement and stress listed in the Table 1. After the initiation of damage, the $d_{I}$ calculated by method $\mathrm{B}$ is larger than that by method $\mathrm{A}$ at the same moment. The $d_{I}$ with a larger value leads to the consequence that the stiffness matrix degenerates more severely. Before the impact force reaching the peak value, there are some moments when the in the method $\mathrm{B}$ reached the maximum but the $d_{I}$ in the method A did not, which results in the stiffness matrix $C_{d}$ of method B degenerating more continuously. Moreover, compared to the cases of the relative larger impact energy, all the normal stress components in the lower impact energy are so small that the presence of $\sigma_{33}$ in the method B affects $d_{I}$ and $C_{d}$ more. Furthermore, the impact time at which the force obtained by method A reaches the maximum value is always earlier than method B. After the peak value, the impactor is going to rebound and both of the numerical results take a little longer time to reach zero than the experimental data. Due to the higher impact energy, more contact time is recorded, which leads to more serious damage in the composite. Overall, the predicted force-time curves of both methods match with the experiment data reasonably well, especially while the load is increasing.

Fig. 3 demonstrates the impact force-displacement curves under three impact energy levels. As can be seen, a similar tendency between two methods is observed in the three energies. The maximum displacement predicted from method B is always slightly larger than method A. By comparison of Fig.
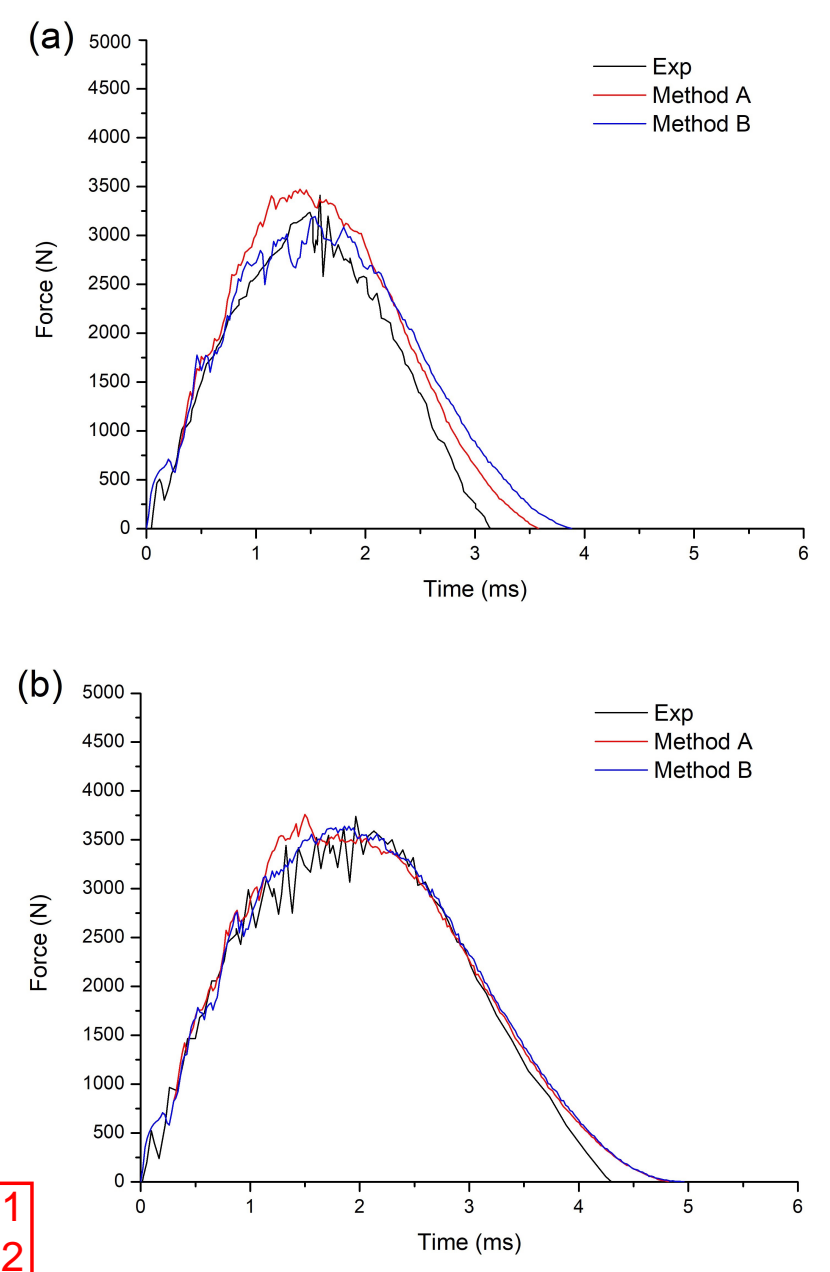

\section{$R 1-1$
$R 2-2$}

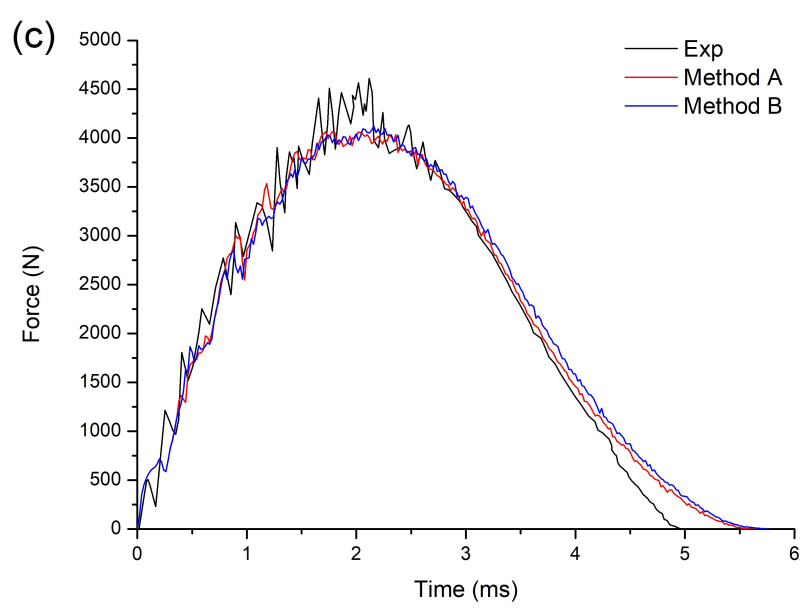

Figure 2: Numerical and experimental impact force-time curves under three impact energy levels (a) $7.35 \mathrm{~J}$ (b) $11.03 \mathrm{~J}$ (c) $14.70 \mathrm{~J}$

$3(\mathrm{a}-\mathrm{c})$, the divergence between the curves achieved by the two methods decreases with increasing the impact energy. Like the force-time diagram, the curves of $14.7 \mathrm{~J}$ obtained by method A and method B are substantially the same in Fig. 3(c). When 

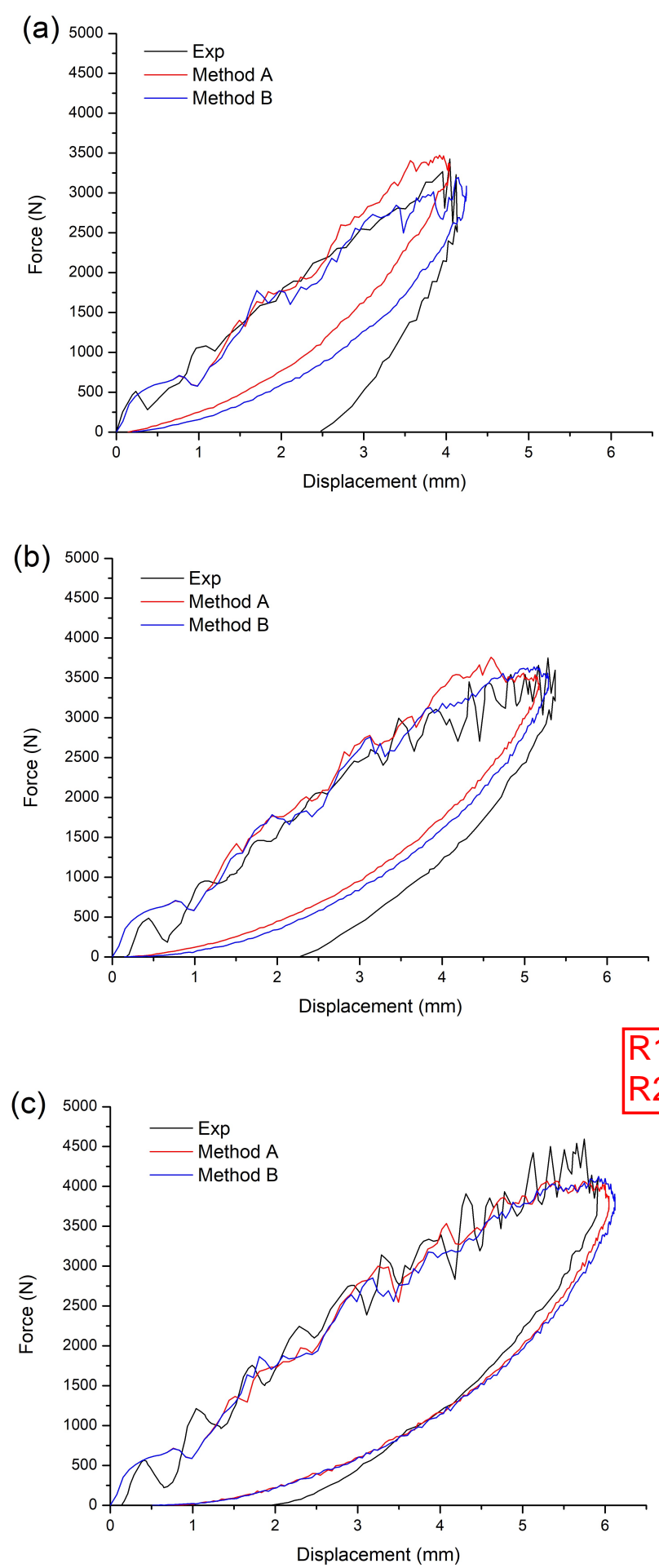

Figure 3: Numerical and experimental impact force-displacement curves under three impact energy levels (a) $7.35 \mathrm{~J}$ (b) $11.03 \mathrm{~J}$ (c) $14.70 \mathrm{~J}$

the force is reduced to zero, the displacements from the numerical results are always smaller than the experiment, especially in the case of the lowest energy, $7.35 \mathrm{~J}$ impact, as shown in Fig. 3(a). Although the numerical results do not match the experi- ment well in the final distance, the deviation between simulation and experiment narrows as the impact energy increases. It should be noted that the experimental displacement was measured from the rebounding impactor [21], while the numerical values are obtained from center of the plate surface. This difference and other factors like friction coefficient used in the simulation may have some influence on the numerical results which show a more complete recovery than the experiment.

Fig. 4 shows the impact energy-time variations under three impact energies. The initial kinetic energy of the impactor begins to transfer to the composite plate as soon as the contact occurs. During the process of impact, part of the kinetic energy is absorbed by the elastic deformation, while most of the energy is dissipated by intra-laminar damage, delamination and the friction. When the velocity of the impactor turns to zero, the energy reaches the maximum value. After the peak point, the elastic energy of the laminates drives the impactor to rebound. In the final state, the energy absorbed by the composite reaches a stable value due to the damage and friction. Compared to the experimental results, the predicted values always lower than the measured value, while the deviation between them narrows as the impact energy increases, especially in Fig. 4(c). It is worth mentioning that the absorbed energy obtained by method $\mathrm{B}$ is always closer to the experimental data than the energy obtained by method A, but the differences become smaller with the increase of impact energy. In the numerical model, the friction coefficients are used between the impactor and the plate, as well as ply-to-ply in the laminate. It is hard to adopt the accurate realistic friction coefficients to simulate the contact, especially the contact between the two adjacent composite layers after delamination. Besides, the values of fracture energy used in the cohesive elements also have effects on absorbing energy. Therefore, a parametric study on the cohesive element should be done in the future. These factors may lead to the result that the predicted values of absorbed energy are always lower than the measured values. With impact energy increasing, more and more elements in the impact zone become complete failure, instead of partial damage where the energy absorption is unable to predict precisely due to the complex process of damage accumulation. This may be one of the reasons that the deviation between the predicted value and the measured value narrows as the impact energy increases. Another explanation for this phenomenon is that the method A ignores the through-thickness normal stress $\sigma_{33}$ when applying the equivalent displacement method to damage evolution model. It can be a considerable practical approach when the state of stress in the laminae is far enough away from the edges of a laminate. However, the through-thickness compression stress is taken to have exactly the same effect as the through-thickness tension stress on delamination [17]. By adding the $\sigma_{33}$ in the damage evolution model makes the method B physically more realistic. In order to provide the effects of $\sigma_{33}$, the triaxial normal stresses of the central element on the back side are list in the Table 4 . The time is $0.3 \mathrm{~ms}$ when the difference in performance does not appear. As can be seen from the Table $4, \sigma_{33}$ is quite small compared to $\sigma_{11}$ and $\sigma_{22}$, the presence of $\sigma_{33}$ in the method B has a slight effect on prediction. With the impact energy increasing, the 

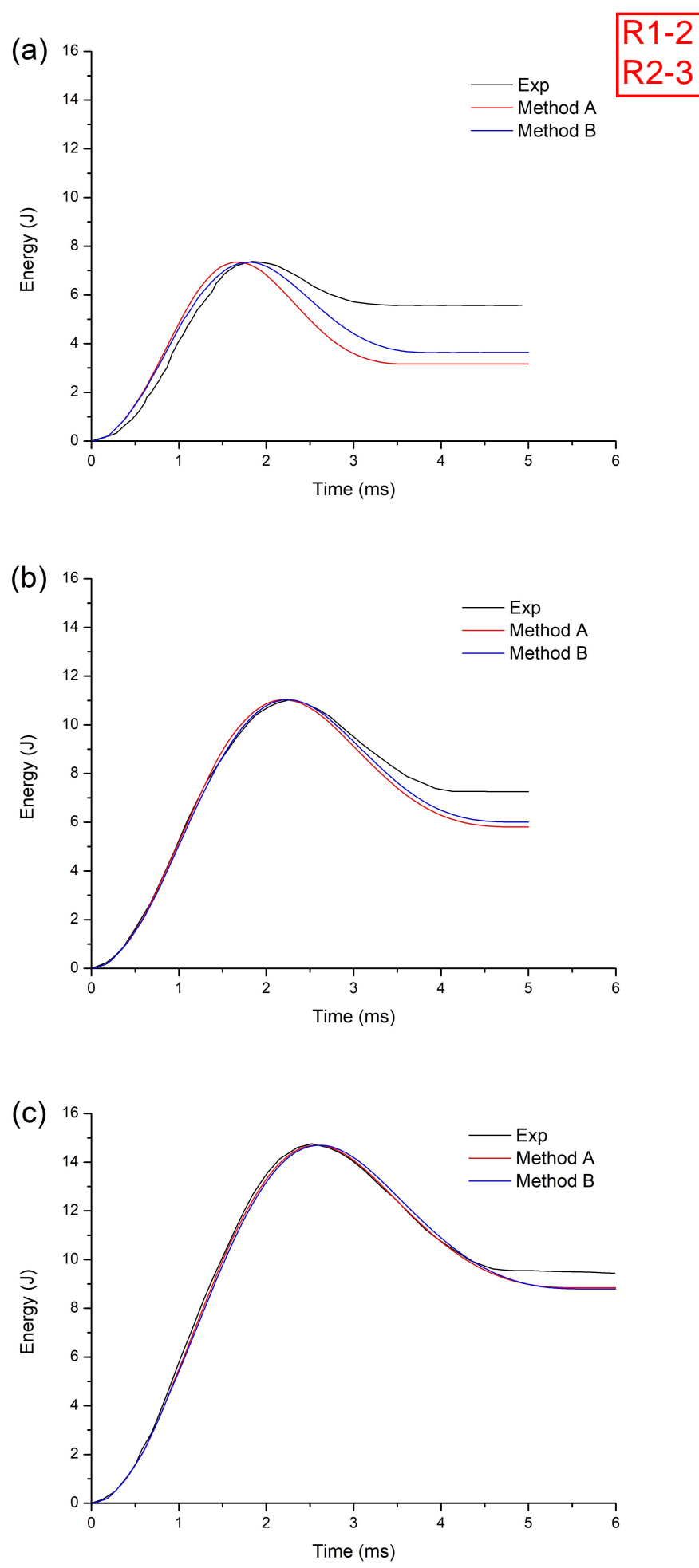

Figure 4: Numerical and experimental impact energy-time curves under three impact energy levels (a) $7.35 \mathrm{~J}$ (b) $11.03 \mathrm{~J}$ (c) $14.70 \mathrm{~J}$

absolute increment of $\sigma_{11}$ grows significantly more than that of $\sigma_{33}$, which results in the circumstance that the effects of $\sigma_{33}$ gradually reduce and the gap between the two methods narrows. Although the $\sigma_{33}$ is quite small compared to $\sigma_{11}$ and $\sigma_{22}$, the presence of $\sigma_{33}$ in the method B has a slight positive effect on predicting the absorbed energy. Besides, damage prediction obtained by the method B may be suitable for some loading cases where out-of-plane stresses are significant.

Table 4: The normal stresses of the central element on the back side

\begin{tabular}{llll}
\hline Impact Energy & $\sigma_{11} / \mathrm{MPa}$ & $\sigma_{22} / \mathrm{MPa}$ & $\sigma_{33} / \mathrm{MPa}$ \\
$7.35 \mathrm{~J}$ & 725.21 & 65.51 & -6.56 \\
$11.03 \mathrm{~J}$ & 731.87 & 65.39 & -6.74 \\
$14.70 \mathrm{~J}$ & 735.80 & 65.12 & -6.80 \\
\hline
\end{tabular}

\subsection{Analysis of damage modes}

Matrix damage and delamination are easy to occur even under small impact energy, while fiber damage usually occurs with higher impact energy. Although these damages are not obvious seeing from the outside surfaces of the laminates, they have essential effects on the residual mechanical performance of the composite structures. Therefore, it is necessary to analyze these damage modes in details.

The matrix tensile damage distribution in each layer of the numerical models of $11.03 \mathrm{~J}$ impact when adopting the two methods are shown in Fig. 5. The red region represents the place where elements failed completely, while the blue means undamaged regions defined for all the damage contours in this work. As can be seen, the damage occurs around the impact point, while the area of the top four layers is smaller than that of the back four layers. Furthermore, it is evident that for both methods, the predicted matrix tensile damage area is larger when the corresponding layer is farther away from the impact side, expect the last layer. This can be explained by the deformation and failure mechanism of the laminates that matrix tensile damage initiates on the back side and expands to the upper layers [34]. Concerning the damage shape, although the last two layers are $90^{\circ}$ layer and $0^{\circ}$ layer respectively, they both look like the butterfly type. The shapes of the remaining layers are approximately rectangular with the long sides along the fiber direction, except the top ply. In addition, the predicted damage contours of method A exhibit a tiny hollowed shape in the center of each top six layers, while this shape is only found in the top four layers of method B. This phenomenon is attributed to the Hashin criterion which uses the summation of transverse and out-of-plane normal stress to evaluate the tension and compression failure for matrix. On the other hand, considering that $\sigma_{33}$ is adopted in the damage evolution model when calculating the equivalent stresses and displacements, the method B has the smaller area and the less number of layers with the hollow shape than the method A. Overall, there are no much differences in predicting matrix tensile damage between those two methods.

Fig. 6 displays the predictions of matrix compression damage in every ply under $11.03 \mathrm{~J}$ impact. Obviously, the matrix compression damage is detected in every ply as same as the matrix tensile damage. However, the deviation of matrix compression damage prediction between those two methods is 
(a)
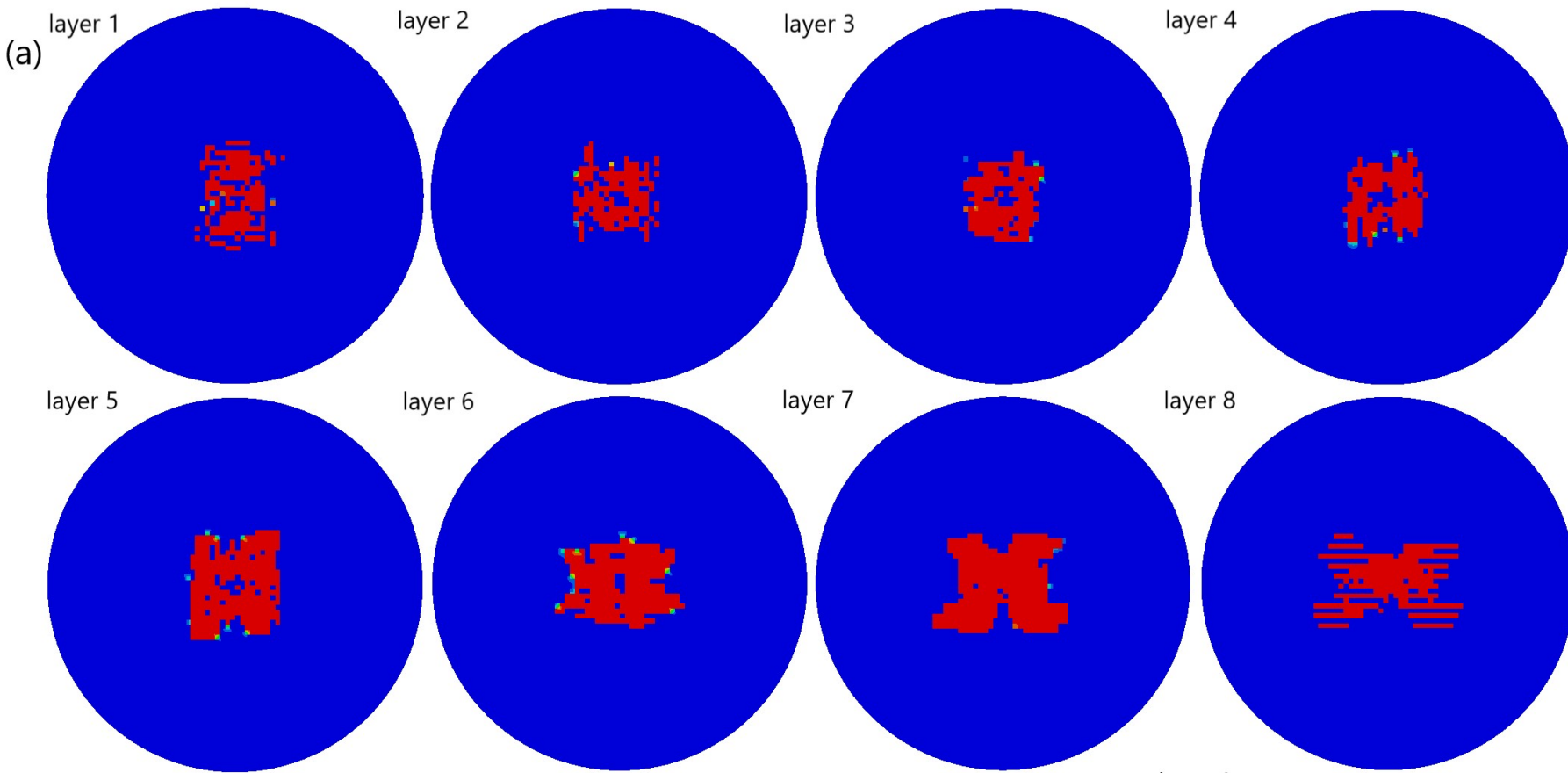

layer 7

layer 8

(b)

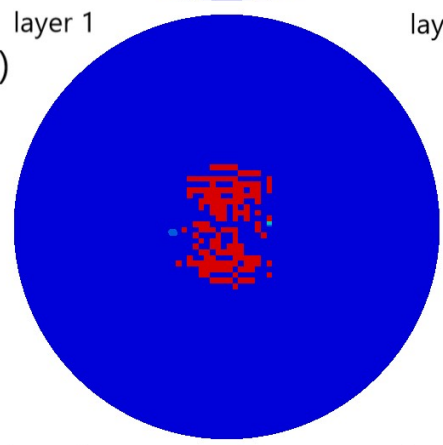

layer 2
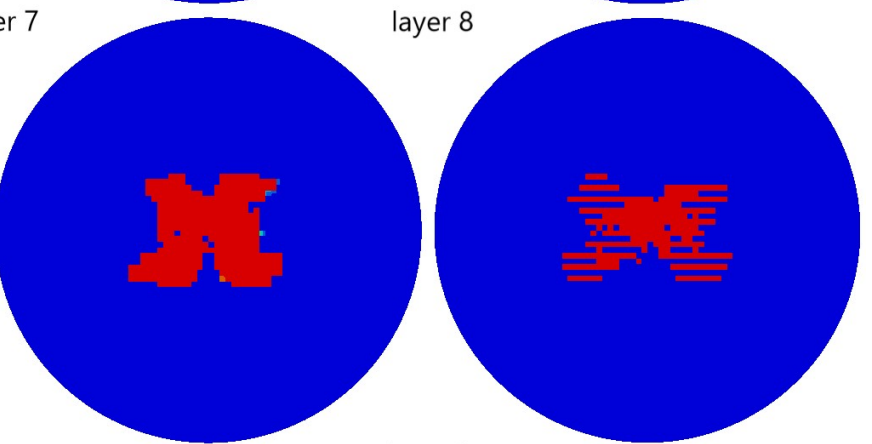

layer 4

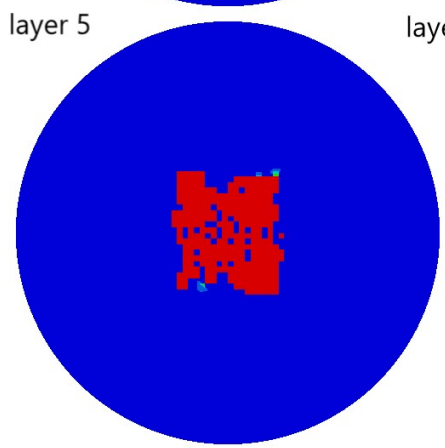

layer 6

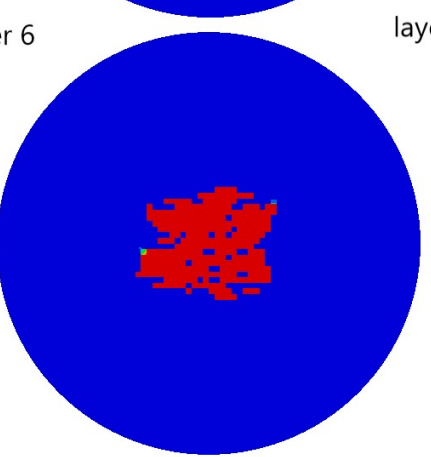

layer 3

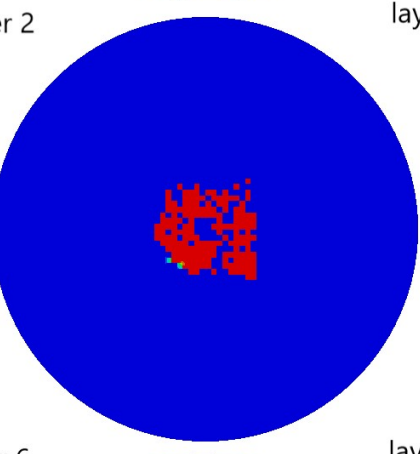

layer 7
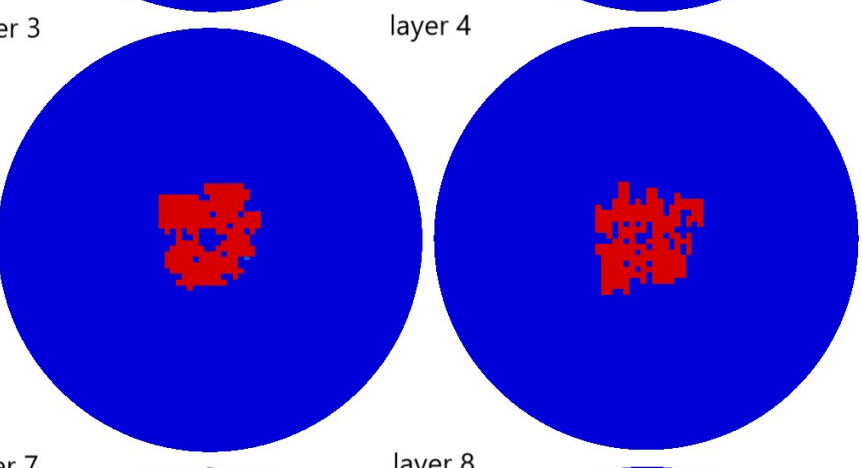

layer 8
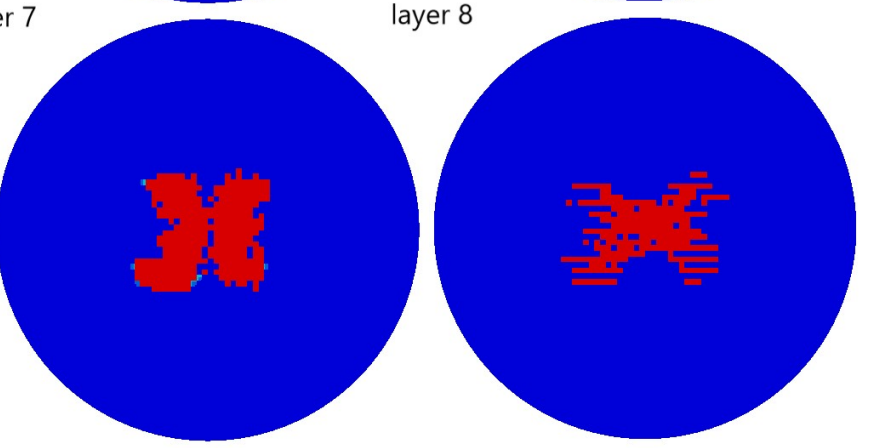

Figure 5: Comparison of predicted matrix tensile damage in each layer of the cross-ply composite laminates under $11.03 \mathrm{~J}$ impact (a) Method A (b) Method B

more significant than that of matrix tensile damage. To be more specifically, the damage area of each ply resulted from method $\mathrm{B}$ is larger than that obtained by method A, where many partial degradations are found in the top three plies, shown in green in Fig. 6(a). In other words, the damages of these regions are not severe so that these parts of the laminates still have the certain load-bearing capacity. Meanwhile, the last two layers, which are the most damaged layers in the mode of matrix tensile damage, have the less damages among the laminates. This finding can be explained that the matrix compression damage first ini- tiates on the impact side and propagates to the bottom, so that more damage areas are found in the top four layes. Since the damaged elements are not deleted in the simulation, the impact contact is only considered between the impactor and the first layer of the laminates, resulting in the fact that the compressive damage at the upper layers is much higher than that at the lower layers. For the majority of layers, the area of matrix compression damage is fewer than that of matrix tensile damage analyzed before, which means that the damage variable $d_{m c}$ has less effect on the damage evolution model than $d_{m t}$ does. 
(a)
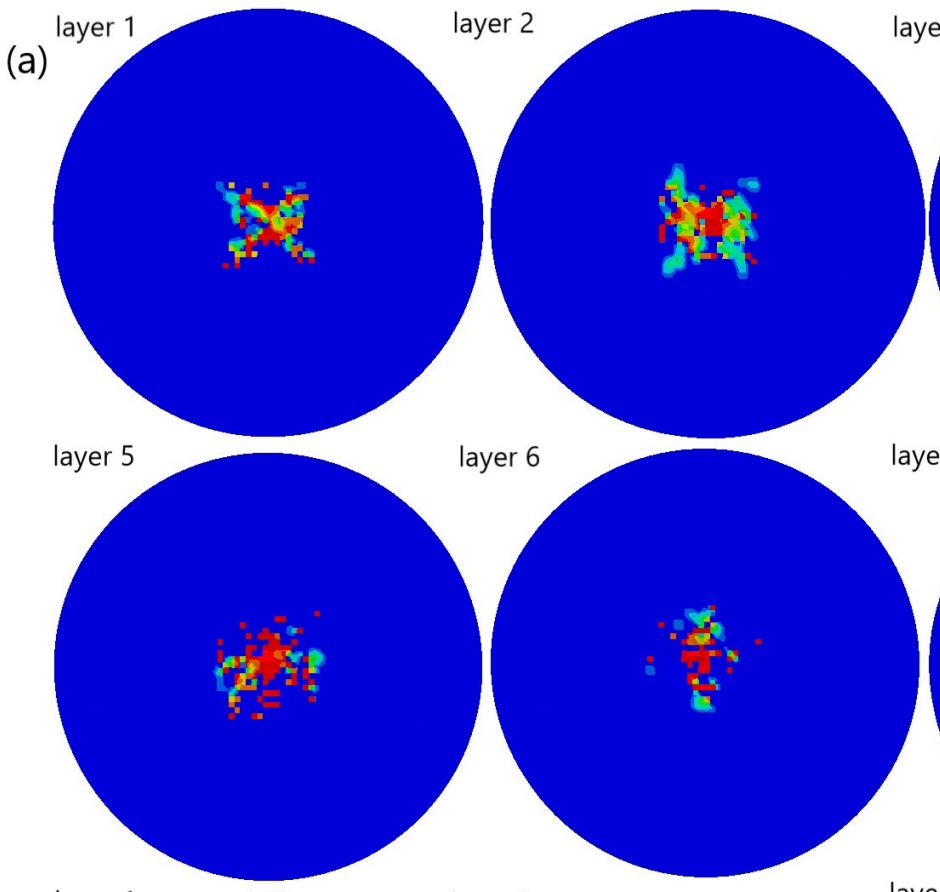

layer 6

(b)

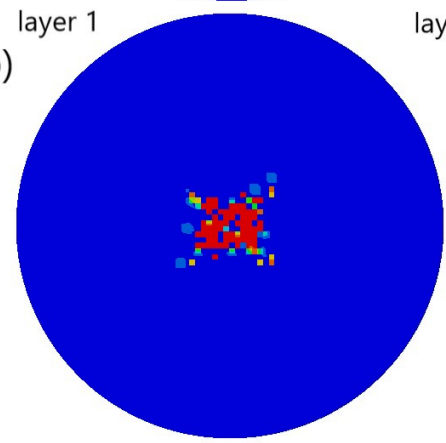

layer 2

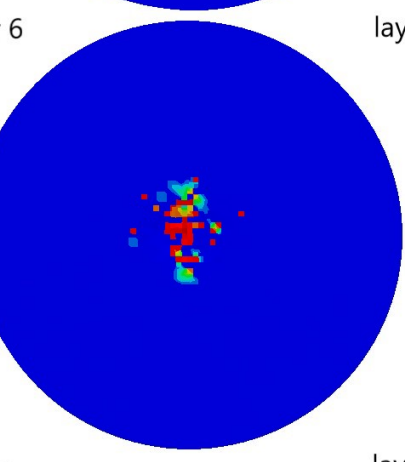

layer 7
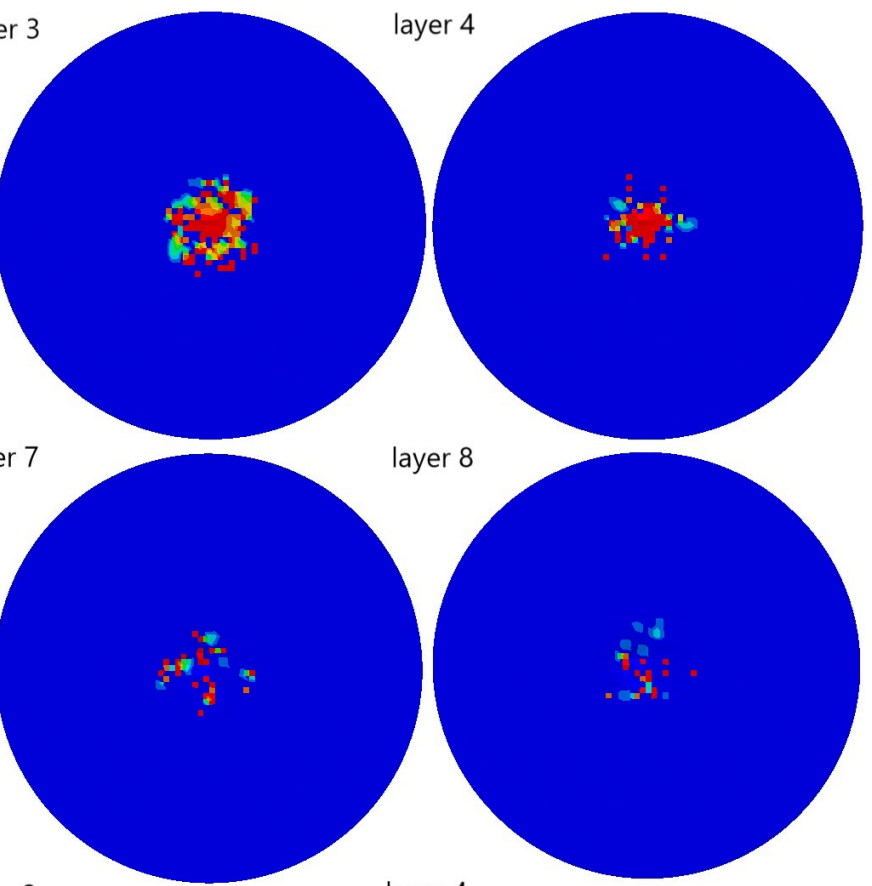

ayer 8

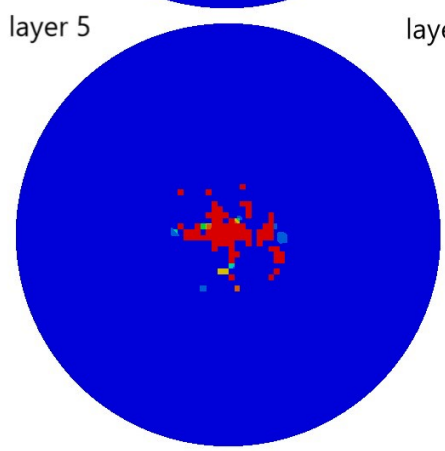

layer 6

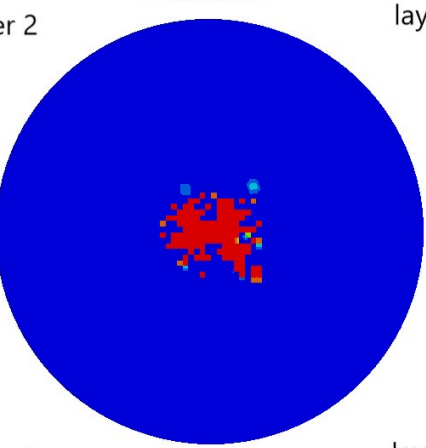

ayer 3

layer 4
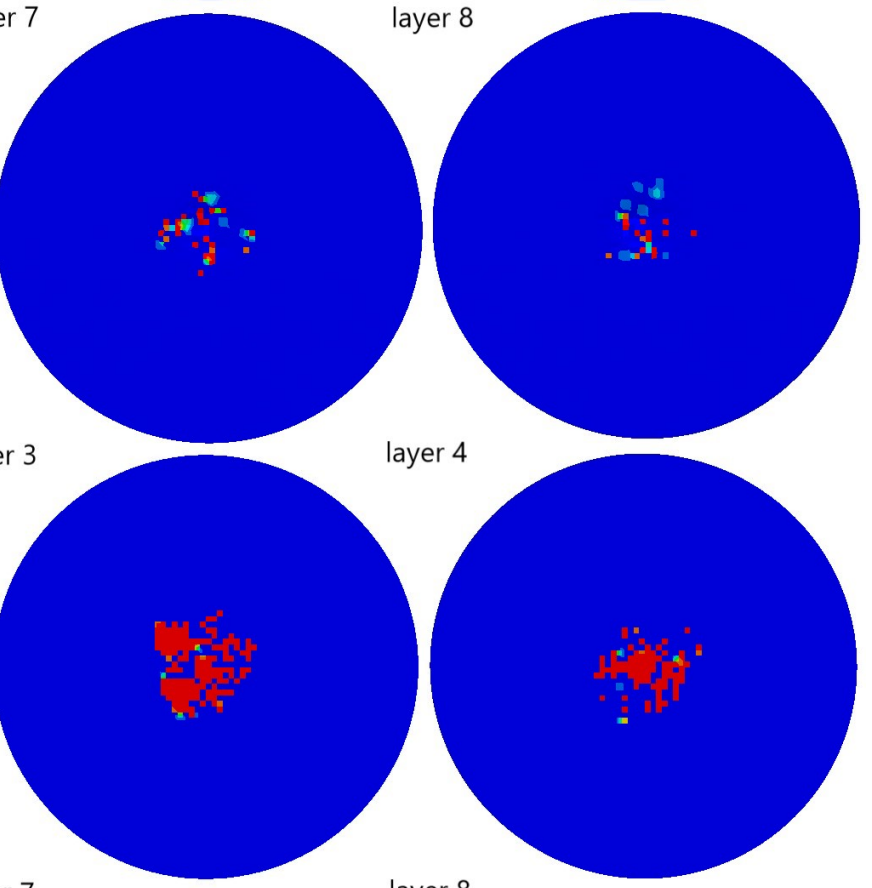

layer 7

layer 8
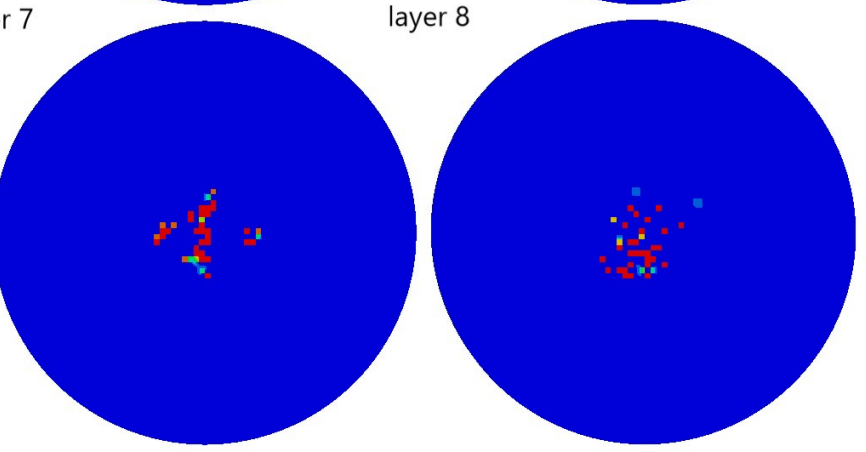

Figure 6: Comparison of predicted matrix compression damage in each layer of the cross-ply composite laminates under $11.03 \mathrm{~J}$ impact (a) Method A (b) Method B

Considering the direction of the fiber, the matrix compression damage does not extend along the fibre direction but concentrates on the impact point and seldom propagates in other directions. In the impact zone, the multiaxial state of stress which is nearly a hydrostatic compression [35] may reinforce the apparent strength of the material and prevents the creation of cracks and delamination, which could justify the gap between experiments and numerical results. In reality, compression improves the delamination strength while even small tensile stress by itself can cause delamination, which is ignored by the method $\mathrm{A}$ due to the lack of $\sigma_{33}$ in the damage evolution model. This could be another reason for the differences between the two methods. However, according to the experiments provided by Y.Shi [21] the fiber failure was not found in the cases of 7.35J and 11.03J impact. In order to avoid predicting multiple yarn failures close to the impactor under the relative larger energy impact, the influence of the hydrostatic pressure on the numerical simulation should be taken into consideration in the further work. In a word, these differences in evaluating the matrix compression damage with the two methods indicate that the re- 
sults predicted by method A are more conservative than that by method B.

The delamination areas of the cross-ply composite laminates under $14.70 \mathrm{~J}$ impact are shown in Fig. 7 to compare the two numerical predicted areas and the X-ray radiograph. All the delaminations are represented in rainbow colour. From the Figs. 7(a-c), the delamination evolution areas which include the complete and partially failed region are larger than that by experiment. More specifically, the delamination area and the complete failure area predicted by method B are larger than those of method A. The details of delamination damage contours for each interface layer are revealed in the Figs. 7(d-e). As can be seen, delamination occurrs in every interface with varying degrees of damage. The two methods predict the similar areas of severe delaminations when the damage variable is equal to 1 , except for the first and third interfaces. The delamination propagation in the upper interfaces may be constrained by the high friction force due to the impactor. The complete delamination area of method A in interface 1 is larger than that of method $\mathrm{B}$, while method $\mathrm{B}$ predicts more severe delamination in interface 3 than method $A$. The interface 3 and 4 present the most extensive damage areas among the seven interfaces, which is consistent with the conclusions by Shi [21] and Zhang [36]. In addition, the delamination that occurs in the interface 7 is basically completely ineffective, with few partial failures. For the last four interfaces, the damage propagation direction is parallel to the fiber orientations of the lamina below the corresponding interface, which is consistent with the conclusions given by Liu [10] and Li [37]. Nevertheless, the distribution of delamination damage in the top three interfaces does not match the aforementioned regulations. The predicted delamination areas depend on the element size and the material properties of interface cohesive element. Applying more appropriate parameters in the model may result in a better prediction, which makes the predicted delamination area closer to the actual situation. However, the delamination areas predicted by simulations are larger than that by experiment, which leads to a more conservative result when designing the allowable values for composites via the numerical model. In other words, the larger delamination evolution area can prompt designers to improve the allowable values for composite materials better. As mentioned before, the through-thickness stress has some effects on delamination, which could be the reason for the slightly larger delamination area predicted by method B.

Using C-Scan as a function of the impact energy levels for configuration would definitely improve the quality of this manuscript. Unfortunately, the experimental data obtained from Shi [21] didn't include the C-Scan results. Therefore, another numerical simulation is implemented to compare the test data taken from the work of N. Hongkarnjanakul [27]. A T700CG/M21 carbon/epoxy composite laminate with stacking sequences of $\left[0_{2}, 45_{2}, 90_{2},-45_{2}\right]_{S}$ subjected to $25 \mathrm{~J}$ impact and a geometry size of $100 \times 150 \times 4 \mathrm{~mm}$ are adopted here for the further validation. The detailed material properties for this composite are listed in Table 5. Fig.8 shows the experimental and numerical delamination results of the T700CG/M21 composite laminates under $25 \mathrm{~J}$ impact. As can be seen, the predicted distribution of delamination damage correlates reasonably well with the experimental data, except showing the slightly larger areas. More specifically, the delamination area and the complete failure area predicted by method B are still larger than those of method A, which is consistent with the foregoing conclusions.

$$
\text { R1-5 }
$$

Table 5: Material properties for T700CG/M21 composite laminates

\begin{tabular}{|c|c|c|}
\hline \multirow{4}{*}{$\begin{array}{l}\text { Composite } \\
\text { lamina } \\
\text { properties }\end{array}$} & Density & $1600 \mathrm{~kg} / \mathrm{m}^{3}$ \\
\hline & $\begin{array}{l}\text { Stiffness } \\
\text { properties }\end{array}$ & $\begin{array}{l}E_{11}=130 \mathrm{GPa} ; E_{22}=E_{33}=7.7 \mathrm{GPa} \\
G_{12}=G_{13}=4.8 \mathrm{GPa} ; G_{23}=3.8 \mathrm{GPa} ; \\
v_{12}=v_{13}=0.33 ; v_{23}=0.35\end{array}$ \\
\hline & $\begin{array}{l}\text { Strength } \\
\text { properties }\end{array}$ & $\begin{array}{l}X_{T}=2080 \mathrm{MPa} ; X_{C}=1250 \mathrm{MPa} \\
Y_{T}=60 \mathrm{MPa} ; Y_{C}=140 \mathrm{MPa} \\
S_{12}=S_{13}=S_{23}=110 \mathrm{MPa}\end{array}$ \\
\hline & $\begin{array}{l}\text { Fracture } \\
\text { energy }\end{array}$ & $\begin{aligned} G_{f t} & =133 \mathrm{~N} / \mathrm{mm} ; G_{f c}=40 \mathrm{~N} / \mathrm{mm} ; \\
G_{m t} & =0.6 \mathrm{~N} / \mathrm{mm} ; G_{m c}=2.1 \mathrm{~N} / \mathrm{mm}\end{aligned}$ \\
\hline \multirow{4}{*}{$\begin{array}{l}\text { Interface } \\
\text { properties }\end{array}$} & $\begin{array}{l}\text { Elastic } \\
\text { modulus }\end{array}$ & $E_{n}=E_{s}=E_{t}=5 \mathrm{GPa} / \mathrm{mm}$ \\
\hline & $\begin{array}{l}\text { Strength } \\
\text { properties }\end{array}$ & $N=S=T=30 \mathrm{MPa}$ \\
\hline & $\begin{array}{l}\text { Fracture } \\
\text { energy }\end{array}$ & $\begin{array}{l}G_{m t}=0.6 \mathrm{~N} / \mathrm{mm} \\
G_{m c}=2.1 \mathrm{~N} / \mathrm{mm}\end{array}$ \\
\hline & $\begin{array}{l}\text { Relevant } \\
\text { coefficient }\end{array}$ & 1.45 \\
\hline
\end{tabular}

Overall, the computational algorithm realized by the VUMAT subroutine and the dynamic progressive damage models obtained by two methods are considered to be verified, with a capability to predict well the dynamic progressive damage of a composite laminate under low-velocity impact. The proposed method B is based on the method A, which mainly modified the damage evolution model. The prediction obtained by the improved method with $\sigma_{33}$ is closer to the test data than the original, which means that the method proposed in the present study is more suitable for low-velocity impact on composite laminates under different impact energies. Although the difference R2-1 in performance between the methods is not significant, adding the through-thickness normal stress component $\sigma_{33}$ makes the method B physically more realistic. Moreover, the damage prediction obtained by the proposed method with $\sigma_{33}$ may be suitable for some loading cases where out-of-plane stresses are significant. The material properties in the simulation are taken from the work of Y. Shi [21], which had already been used in the literature $[29,36]$. If some properties are changed slightly in the method A, these parameters should also be changed in the method B so that the mechanical response would share the same trend as the current conclusions. Besides, further investigations on microscopic observations of the different damage mechanisms are definitely required to validate the damage modes predicted by method $\mathrm{B}$, which provides the deeper perspectives about the quality of the modelling and the benefits of considering $\sigma_{33}$ in the simulation. 
(a)
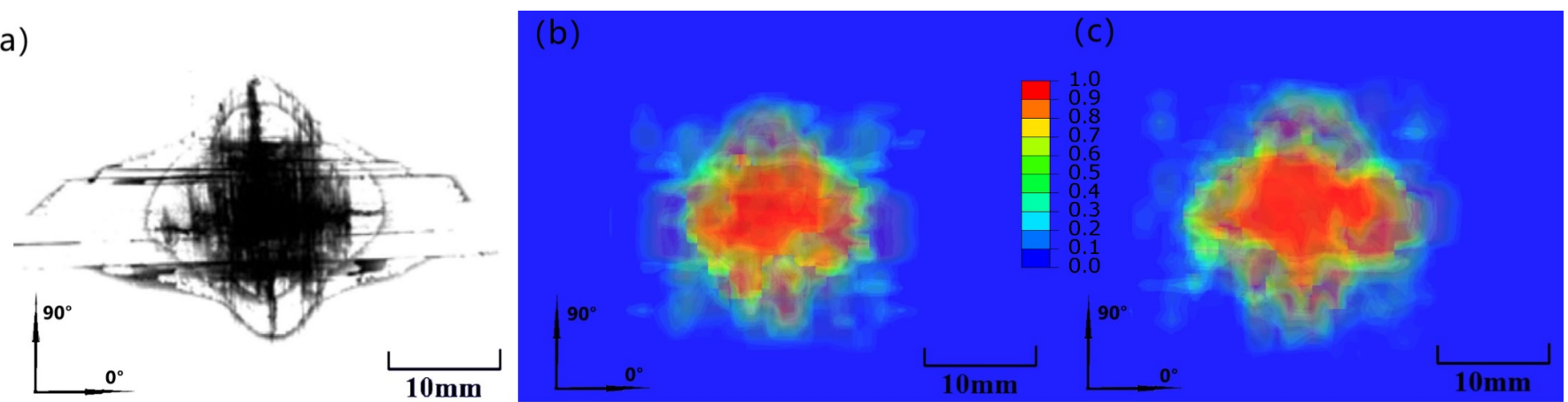

(d)

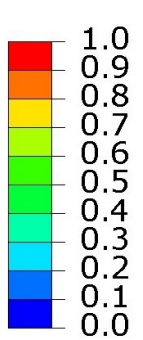

interface 1

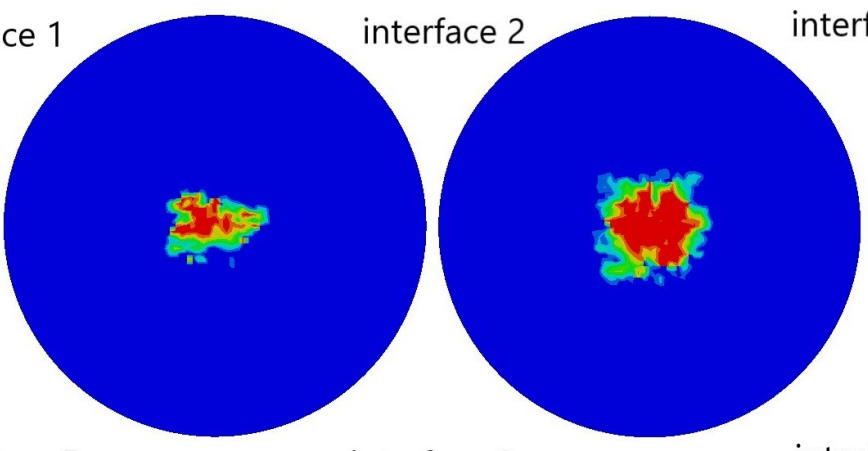

interface 3

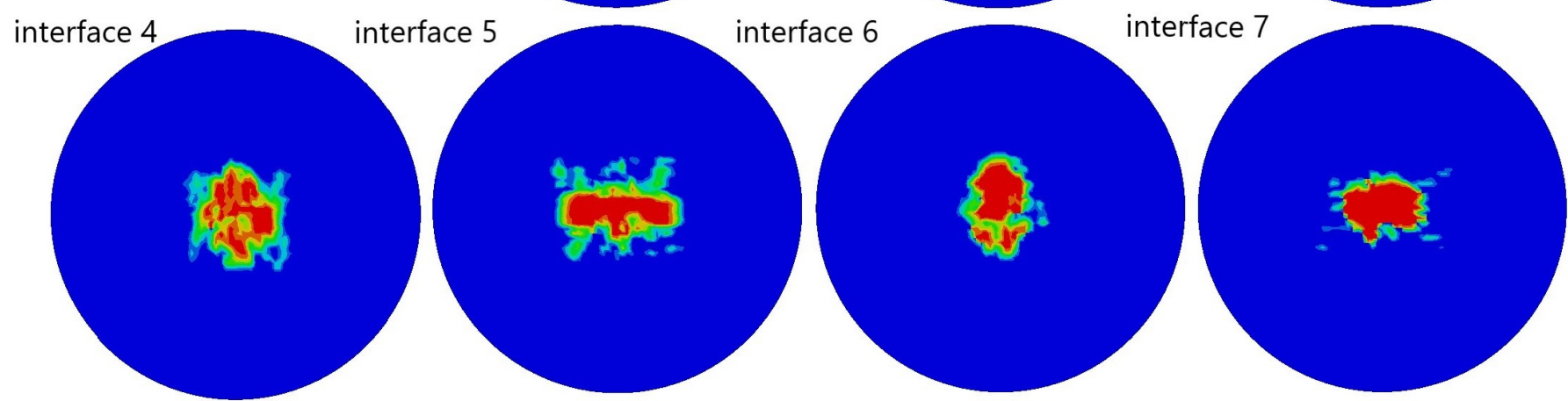

(e)

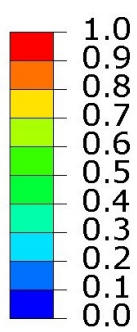

interface 1

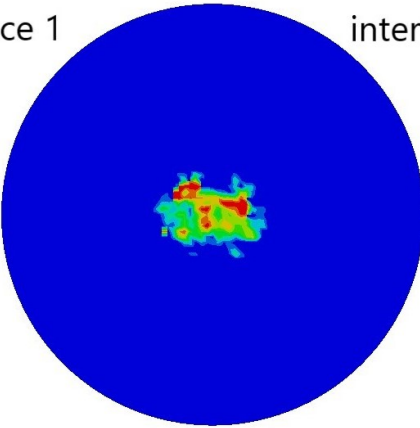

interface 2
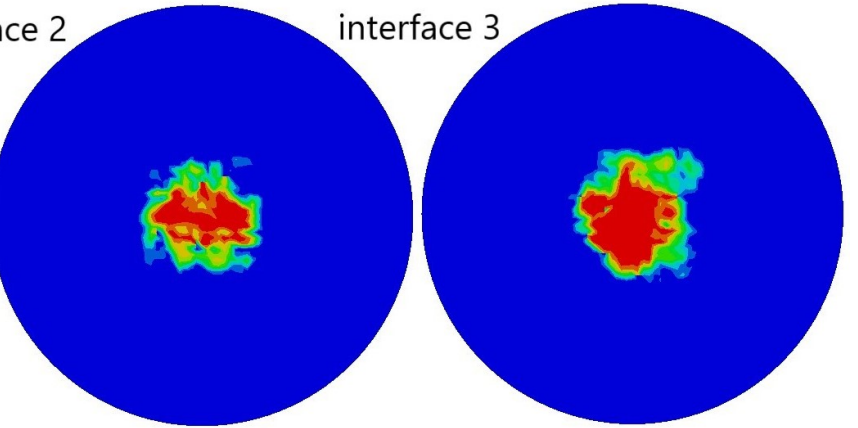

interface 4

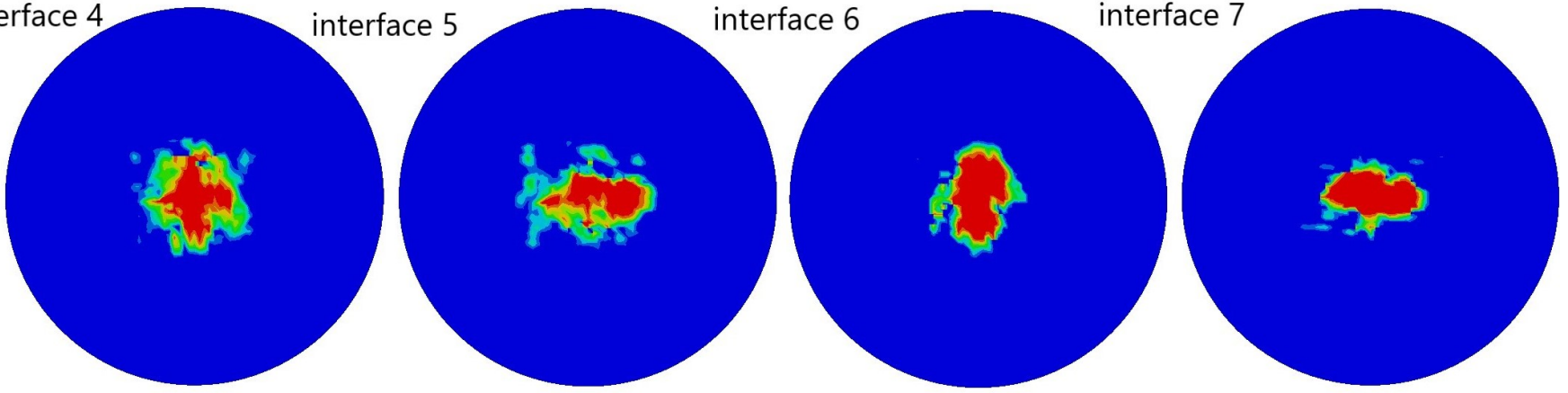

Figure 7: Delamination area of the cross-ply composite laminates under $14.70 \mathrm{~J}$ impact (a) X-ray radiograph (b) Overlapped graph predicted by method A (c) Overlapped graph predicted by method B (d) Each interface delamination predicted by method A (e) Each interface delamination predicted by method B 
(a)

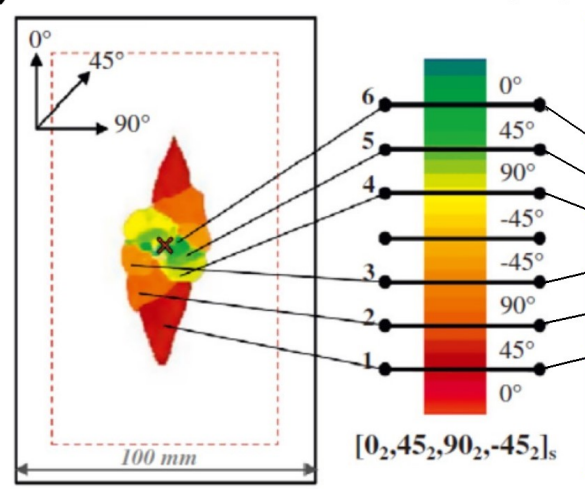

(b)

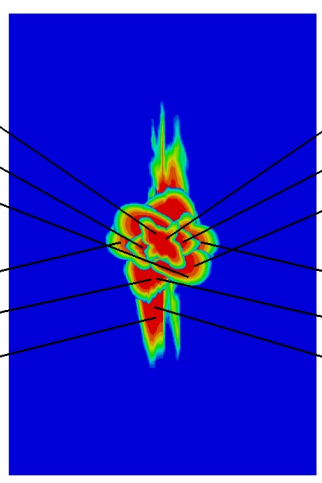

(c)

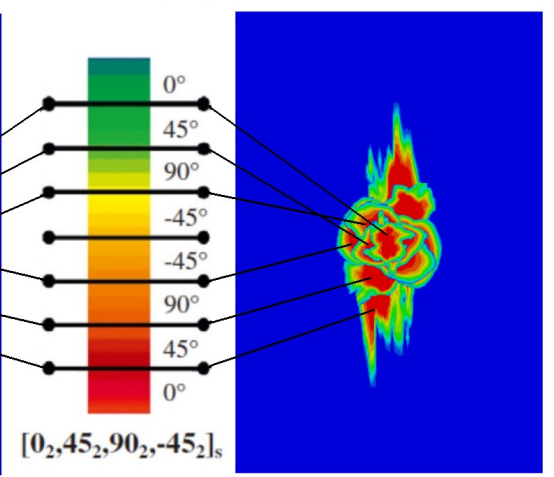

Figure 8: Delamination area of the T700CG/M21 composite laminates under $25 \mathrm{~J}$ impact (a) Experimental C-scan result (b) Overlapped graph predicted by method A (c) Overlapped graph predicted by method B
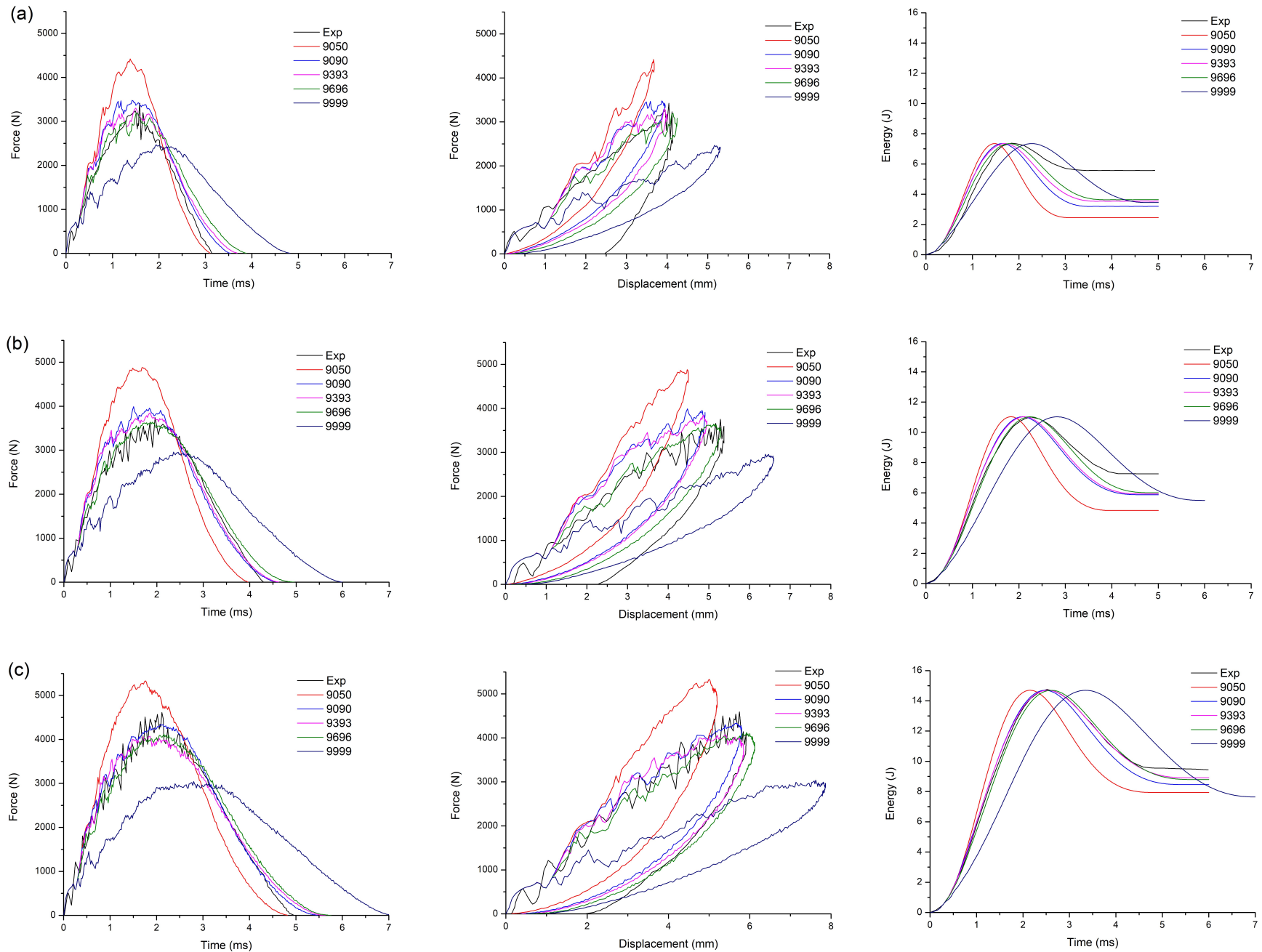

Figure 9: Impact force-time, force-displacement and energy-time curves obtained by different values of $S_{m t}$ and $S_{m c}$ under three impact energy levels (a) $7.35 \mathrm{~J}$ (b) $11.03 \mathrm{~J}(\mathrm{c}) 14.70 \mathrm{~J}$

\subsection{Evaluation of coefficients $S_{m t}$ and $S_{m c}$}

Coefficients $S_{m t}$ and $S_{m c}$ to control the shear stiffness loss were first used in the literature [22]. The main purpose of those two coefficients is to avoid excessive softness of the material which will cause large deformations in the numerical 
calculations so that the results do not converge. In the past literature $[22,10,38,36,39]$, authors used 0.9 and 0.5 as the values of $S_{m t}$ and $S_{m c}$ in the stiffness degradation matrix. Nevertheless, there is no article published to explain why 0.9 and 0.5 were used. There is no doubt that the larger the coefficient, the closer the component of degraded stiffness matrix is to zero. In the present study, $S_{m t}$ and $S_{m c}$ are set to five groups of values, i.e. 0.9 and 0.5, 0.9 and 0.9, 0.93 and 0.93, 0.96 and 0.96, 0.99 and 0.99 , respectively.

Fig. 9 exhibits force-time, force-displacement and energytime curves obtained from the five groups of numerical simulations. In the legend, the number 9050 represents that $S_{m t}$ is taken to 0.9 and $S_{m c}$ is taken to 0.5 , while the number 9999 denotes that both $S_{m t}$ and $S_{m c}$ are taken to 0.99 . Obviously, there is a regular pattern in these sets of coefficients in Figs. 9(ac). With the coefficient increasing, the impact force decreases gradually while impact time, displacement and absorbed energy rise under three impact energy levels. In Figs. 9 (a-b), the error of predicting maximum impact force by the set of 9696 is minimal among the five sets of coefficients, less than $5 \%$. Similarly, the curves of force-displacement and energy-time obtained from 9696 coincide with experimental curves better than the others. However, in the case of $14.70 \mathrm{~J}$, the simulation of both $S_{m t}$ and $S_{m c}$ equal to 0.93 predicts the minimal deviation between numerical and experimental results among the five groups of coefficients, shown in Fig. 9(c). Obviously, the numerical results obtained by setting $S_{m t}$ of 0.9 and $S_{m c}$ of 0.5 do not match the experimental results. The predicted values of force are much larger than the actual values under three impact energy. Meanwhile, the predicted displacement and absorbed energy are far less than the experiment data. In other words, although the composite plate has reached the failure criteria, its stiffness is not seriously degraded. On the contrary, the number 9999 curves show another extreme unrealistic situation. The impact time in this case is significantly longer than other groups. Similarly, the displacement of this case is also much larger than others. Since excessive softening of the stiffness, the impact force is much lower than others. Therefore, neither of these two sets of coefficients can be applied to the present model.

Fig. 10(a) illustrates the matrix tensile damage in the last layer predicted by five groups of numerical simulations of 7.35 $\mathrm{J}$ impact energy. It is clear that the damage area grows as the coefficient increases. Considering the direction of the fiber, the matrix compression damage propagates along the fibre direction which is $0^{\circ}$ in the layer 8 . Besides, the shape of damage area of the group 9999 looks like the capital letter X which is different from the others. Fig. 10(b) demonstrates the predictions of matrix compression damage in the top layer under 7.35 $\mathrm{J}$ impact. With the value of coefficients increasing, more and more severe damages appears. To some extent, it can be considered that the damage shapes of all groups are approximate, which means that the values of $S_{m t}$ and $S_{m c}$ do not affect the matrix compression damage significantly. Fig. 10(c) displays the delaminations of the interface 7 predicted via five groups of numerical simulations of $7.35 \mathrm{~J}$ impact energy. Obviously, only the two groups of 9050 and 9090 have the similar dam-

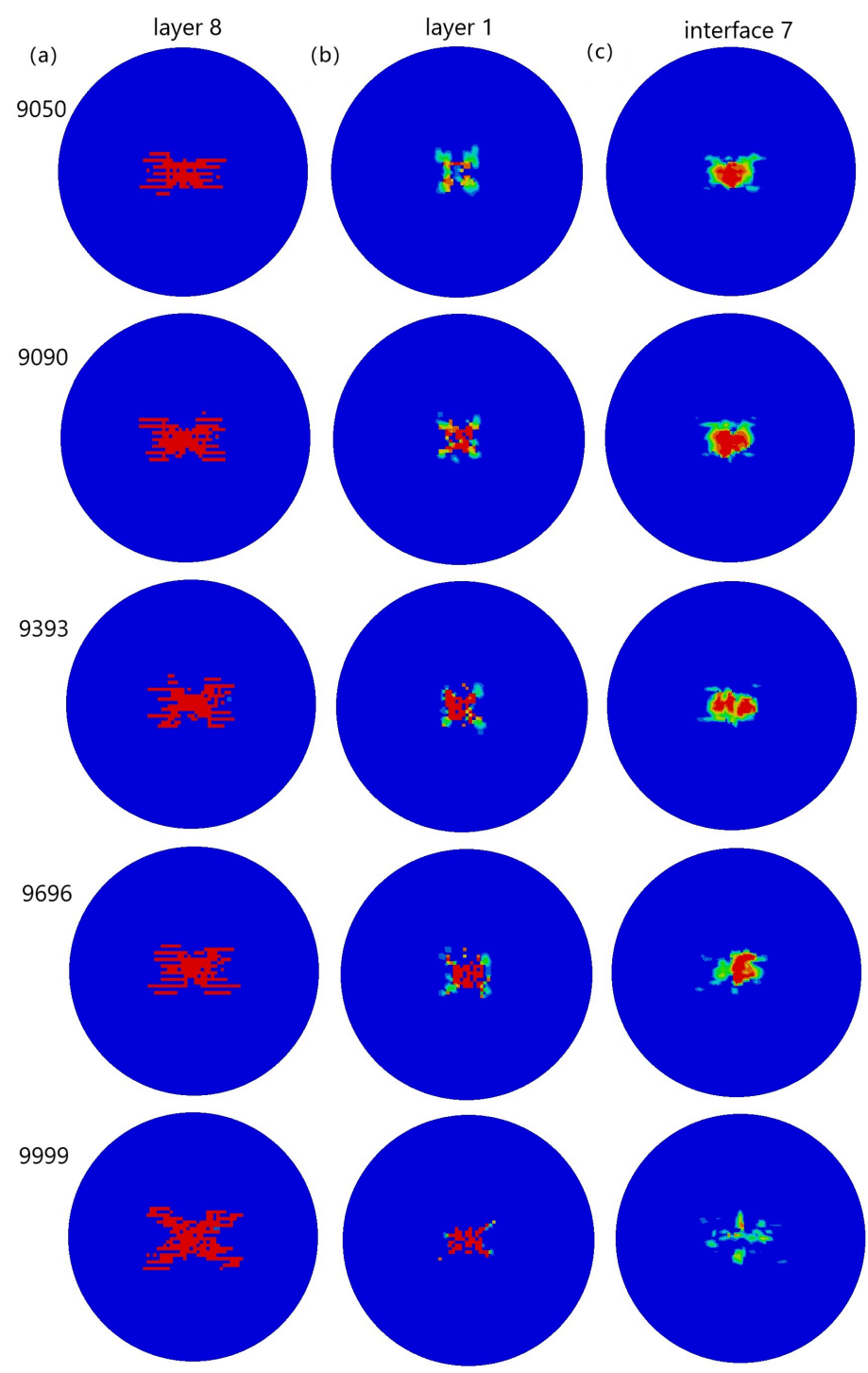

Figure 10: Comparison of damage evaluation in typical layers and interface under impact energy of $7.35 \mathrm{~J}$ (a) Matrix tensile damage (b) Matrix compression damage (c) Delamination

age area, which suggests that $S_{m t}$ effects the delamination more than $S_{m c}$. The remaining groups show the significantly different shapes of delamination. More specifically, there are three, one and zero main red regions in the damage contours of the group 9393, 9696 and 9999, respectively. It is barely to find the severe delaminations where the damage variable is greater than 0.7 in the group 9999, which can be explained that the stress components are too low to satisfy the quadaratic failure criterion due to excessive stiffness loss.

Overall, considering all aspects of factors, $S_{m t}$ and $S_{m c}$ should be adopted between 0.93 and 0.96 when using this damage model to simulate composite laminates under low-velocity impact. 


\section{Conclusions}

In this paper, a PDM based on finite element model incorporates intra-laminar and inter-laminar damage is proposed to predict the dynamic mechanical response and damage development of cross-ply composite laminates subjected to low velocity impact. The three-dimensional Hashin criterion is implemented to predict damage initiation and a modified computational method of equivalent displacement is proposed to avoid ignoring the through-thickness normal stress component $\sigma_{33}$ in the damage evolution model. Delamination is simulated by inserting zero thickness cohesive elements where the bilinear traction-separation law, the quadaratic failure criterion and the B-K criterion are applied. The proposed composite damage model is executed in the finite element software ABAQUS/Explicit with a user-material subroutine VUMAT. The numerical results of three different impact energies (7.35, 11.03 and $14.70 \mathrm{~J}$ ) are analyzed by global mechanical response and different damaged modes. Compared with the method without $\sigma_{33}$, the respectable relationship between numerical simulation and experimental data indicates that the proposed method is more suitable for low-velocity impact on composite laminates under different impact energies.

The advantages and benefits of applying the 3D Hashin criterion and the damage evolution model with the throughthickness normal stress component $\sigma_{33}$ for numerical simulation are listed as follows:

- The proposed method with $\sigma_{33}$ is more adequate for predicting the peak force, maximum displacement, and impact contact time compared with experimental test data when simulating the impact event subjected to the lower levels of energy. However, the positive influence of considering $\sigma_{33}$ is gradually diminished as the impact energy increases.

- Although the predicted absorbed energies are always lower than the measured values, the proposed method is always closer to the experimental data. With the impact energy increasing, it also shows the same trend that the deviation between the two numerical methods narrows.

- The delamination predicted by the proposed method shows the larger area than the test data, which means that the 3D Hashin criterion and the damage evolution model with $\sigma_{33}$ could be a good choice for composite design and engineering applications due to its conservative prediction and simple expression.

- The proposed method is considered physically more realistic due to the involvement of $\sigma_{33}$ in the damage evolution model. Therefore, the damage prediction obtained by this method may be suitable for some loading cases where outof-plane stresses are significant.

Based on the global mechanical responses and the damage evaluation of typical layers, the effect of $S_{m t}$ and $S_{m c}$ on numerical simulation is discussed. Although both of the coefficients have more or less influence on the predicted results, the coefficient $S_{m t}$ affects the inter-lanimar damage more than $S_{m c}$ does. With the parameter study, we conclude that both of the coefficients should be adopted between 0.93 and 0.96 when using this damage model to simulate composite laminates under low-velocity impact.

Although the cross-ply composite laminates under three levels of impact energy are observed by the proposed composite damage model, this damage model can be utilized directly to analyze the damage development behavior in other types of composite laminates under low-velocity impact of different energies.

\section{Acknowledgment}

Junjie Zhou would sincerely like to thank the China Scholarship Council for supporting his study in Queen Mary University of London.

\section{References}

[1] S. Abrate, Impact on composite structures, Cambridge university press, 2005.

[2] R. Bogenfeld, J. Kreikemeier, T. Wille, Review and benchmark study on the analysis of low-velocity impact on composite laminates, Engineering Failure Analysis 86 (2018) 72-99.

[3] P. F. Liu, J. Y. Zheng, Recent developments on damage modeling and finite element analysis for composite laminates: A review, Materials \& Design 31 (8) (2010) 3825-3834.

[4] A. Faggiani, B. G. Falzon, Predicting low-velocity impact damage on a stiffened composite panel, Composites Part A: Applied Science and Manufacturing 41 (6) (2010) 737-749.

[5] L. Iannucci, J. Ankersen, An energy based damage model for thin laminated composites, Composites Science and Technology 66 (7-8) (2006) 934-951.

[6] I. Lapczyk, J. A. Hurtado, Progressive damage modeling in fiberreinforced materials, Composites Part A: Applied Science and Manufacturing 38 (11) (2007) 2333-2341.

[7] S. Metoui, E. Pruliere, A. Ammar, F. Dau, A reduced model to simulate the damage in composite laminates under low velocity impact, Computers Structures 199 (2018) 34-45.

[8] M. V. Donadon, L. Iannucci, B. G. Falzon, J. M. Hodgkinson, S. F. M. de Almeida, A progressive failure model for composite laminates subjected to low velocity impact damage, Computers Structures 86 (11-12) (2008) 1232-1252.

[9] T. E. Tay, G. Liu, V. B. C. Tan, X. S. Sun, D. C. Pham, Progressive failure analysis of composites, Journal of Composite Materials 42 (18) (2008) 1921-1966.

[10] P. F. Liu, B. B. Liao, L. Y. Jia, X. Q. Peng, Finite element analysis of dynamic progressive failure of carbon fiber composite laminates under low velocity impact, Composite Structures 149 (2016) 408-422.

[11] C. Zhang, N. Li, W. Wang, W. K. Binienda, H. Fang, Progressive damage simulation of triaxially braided composite using a $3 \mathrm{~d}$ meso-scale finite element model, Composite Structures 125 (2015) 104-116.

[12] F. Guo-dong, L. Jun, W. Bao-lai, Progressive damage and nonlinear analysis of $3 \mathrm{~d}$ four-directional braided composites under unidirectional tension, Composite Structures 89 (1) (2009) 126-133.

[13] C.-S. Lee, J.-H. Kim, S.-k. Kim, D.-M. Ryu, J.-M. Lee, Initial and progressive failure analyses for composite laminates using puck failure criterion and damage-coupled finite element method, Composite Structures 121 (2015) 406-419.

[14] Z. Hashin, A.Rotem, A fatigue failure criterion for fiber reinforced materials, Composite Materials 7 (1973) 448-464.

[15] Z. Hashin, Failure criteria for unidirectional fiber composites, Journal of Applied Mechanics 47 (2) (1980) 329-334.

[16] F. Chang, K. Chang, A progressive damage model for laminated composites containing stress concentrations, Composite Materials 21 (1987) $832-855$. 
[17] J. Hou, N. petrinic, C. Ruiz, S. Hallett, Prediction of impact damage in composite plates, Composites Science and Technology 60 (2000) 273281.

[18] J. Hou, N. Petrinic, C. Ruiz, A delamination criterion for laminated composites under low-velocity impact, Composites Science and Technology 61 (2001) 2069-2074.

[19] J. Zhang, X. Zhang, An efficient approach for predicting low-velocity impact force and damage in composite laminates, Composite Structures 130 (2015) 85-94.

[20] J. Zhang, X. Zhang, Simulating low-velocity impact induced delamination in composites by a quasi-static load model with surface-based cohesive contact, Composite Structures 125 (2015) 51-57.

[21] Y. Shi, T. Swait, C. Soutis, Modelling damage evolution in composite laminates subjected to low velocity impact, Composite Structures 94 (9) (2012) 2902-2913.

[22] J. Pederson, Finite element analysis of carbon fiber composite ripping using abaqus, Thesis (2008).

[23] D. Feng, F. Aymerich, Finite element modelling of damage induced by low-velocity impact on composite laminates, Composite Structures 108 (2014) 161-171.

[24] R. Krueger, Virtual crack closure technique: history, approach, and applications, Applied Mechanics Reviews 57 (2) (2004) 109-143.

[25] P. P. Camanho, C. G. Davila, M. F. de Moura, Numerical simulation of mixed-mode progressive delamination in composite materials, Journal of Composite Materials 37 (16) (2003) 1415-1438.

[26] C. Bouvet, B. Castanié, M. Bizeul, J.-J. Barrau, Low velocity impact modelling in laminate composite panels with discrete interface elements, International Journal of Solids and Structures 46 (14-15) (2009) 28092821.

[27] N. Hongkarnjanakul, C. Bouvet, S. Rivallant, Validation of low velocity impact modelling on different stacking sequences of cfrp laminates and influence of fibre failure, Composite Structures 106 (2013) 549-559.

[28] Y. Shi, C. Pinna, C. Soutis, Interface cohesive elements to model matrix crack evolution in composite laminates, Applied Composite Materials 21 (1) (2013) 57-70.

[29] Y. Shi, C. Pinna, C. Soutis, Modelling impact damage in composite lami- nates: A simulation of intra- and inter-laminar cracking, Composite Structures 114 (2014) 10-19.

[30] Z. P. Bažant, B. H. Oh, Crack band theory for fracture of concrete, Matériaux et construction 16 (3) (1983) 155-177.

[31] M. L. Benzeggagh, M. Kenane, Measurement of mixed-mode delamination fracture toughness of unidirectional glass/epoxy composites with mixed-mode bending apparatus, Composites science and technology 56 (4) (1996) 439-449.

[32] J. Schön, Coefficient of friction of composite delamination surfaces, Wear 237 (1) (2000) 77-89.

[33] Q. Bing, C. Sun, Effect of transverse normal stress on mode ii fracture toughness in fiber composites, in: 16th International conference on composite materials, Kyoto, Japan.

[34] X. Lou, H. Cai, P. Yu, F. Jiao, X. Han, Failure analysis of composite laminate under low-velocity impact based on micromechanics of failure, Composite Structures 163 (2017) 238-247.

[35] N. Carrere, F. Laurin, J. F. Maire, Micromechanical-based hybrid mesoscopic $3 \mathrm{~d}$ approach for non-linear progressive failure analysis of composite structures, Journal of Composite Materials 46 (19-20) (2012) 2389_ 2415 .

[36] C. Zhang, E. A. Duodu, J. Gu, Finite element modeling of damage development in cross-ply composite laminates subjected to low velocity impact, Composite Structures 173 (2017) 219-227.

[37] X. Li, D. Ma, H. Liu, W. Tan, X. Gong, C. Zhang, Y. Li, Assessment of failure criteria and damage evolution methods for composite laminates under low-velocity impact, Composite Structures 207 (2019) 727-739.

[38] P. F. Liu, Z. P. Gu, X. Q. Peng, J. Y. Zheng, Finite element analysis of the influence of cohesive law parameters on the multiple delamination behaviors of composites under compression, Composite Structures 131 (2015) 975-986.

[39] S. W. F. Spronk, M. Kersemans, J. C. A. De Baerdemaeker, F. A. Gilabert, R. D. B. Sevenois, D. Garoz, C. Kassapoglou, W. Van Paepegem, Comparing damage from low-velocity impact and quasi-static indentation in automotive carbon/epoxy and glass/polyamide-6 laminates, Polymer Testing 65 (2018) 231-241. 